\title{
A Functional Interaction between the Neuronal Adhesion Molecules TAG-1 and F3 Modulates Neurite Outgrowth and Fasciculation of Cerebellar Granule Cells
}

\author{
Maura Buttiglione, ${ }^{1}$ Jean-Michel Revest, ${ }^{1}$ Ourania Pavlou, ${ }^{2}$ Domna Karagogeos, ${ }^{2}$ Andrew Furley, ${ }^{3}$ \\ Geneviève Rougon, ${ }^{1}$ and Catherine Faivre-Sarrailh ${ }^{1}$ \\ ${ }^{1}$ Laboratoire de Génétique et de Physiologie du Développement, UMR 6545 Centre National de la Recherche \\ Scientifique, Institut de Biologie du Développement de Marseille, Parc Scientifique de Luminy, 13288 Marseille cedex 9 , \\ France, ${ }^{2}$ Department of Basic Science, University of Crete Medical School and Institute of Molecular Biology and \\ Biotechnology, Heraklion, 71110 Crete, Greece, and ${ }^{3}$ Developmental Genetics Programme, University of Sheffield, \\ Sheffield S10 2TN, England
}

F3 and TAG-1 are two closely related adhesion glycoproteins of the Ig superfamily that are both expressed by the axons of cerebellar granule cells. In an in vitro system in which cerebellar granule cells were cultured on monolayers of transfected Chinese hamster ovary $(\mathrm{CHO})$ cells, we show that F3 and TAG-1 interact functionally. F3 transfectants have been shown to inhibit outgrowth and induce fasciculation of granule cell neurites. By contrast TAG-1 transfectants have no effect on these events. However, when TAG-1 is coexpressed with F3, the inhibitory effect of F3 is blocked. Two possible mechanisms may account for this functional interaction: (1) either TAG-1 and F3 compete for the same neuronal receptor, and in favor of this we observed that binding sites for microspheres conjugated with F3 and TAG-1 are colocalized on the granule cell growth cones, (2) or alternatively, F3 and TAG-1 associate in a multimolecular complex after their binding to independent receptors. Extensive co-clustering of F3 with TAG-1 can in fact be achieved by anti-TAG-1 antibody-mediated cross-linking in double-transfected $\mathrm{CHO}$ cells. Moreover, F3 coimmunoprecipitates with TAG-1 in Triton X-100-insoluble microdomains purified from newborn brain. These data strongly suggest that F3 and TAG-1 may associate under physiological conditions to modulate neurite outgrowth and fasciculation of the cerebellar granule cells.

Key words: F3/F11; TAG-1; microdomains; neuronal adhesion glycoprotein; cerebellum; granule cell culture; axonal outgrowth; fasciculation
During cerebellar ontogenesis, the early initiation of axogenesis from granule cells occurs in the premigratory zone, and as soon as granule cells begin to migrate, axons elongate and form fascicles of parallel fibers (Altman, 1972). The granule cells in the premigratory layer already express a wide range of adhesion molecules of the Ig superfamily, including TAG-1/axonin-1 (Yamamoto et al., 1990), F3/F11 (Faivre-Sarrailh et al., 1992), L1/Ng-CAM (Persohn and Schachner, 1987), Bravo/Nr-CAM (Grumet et al., 1991), and N-CAM isoforms (Hekmat et al., 1990). Their temporal and spatial expression patterns are precisely regulated, suggesting they each have specific functions at specific stages of development. However, as a common feature, all of these Ig family members localize at the same time on the surface of growing parallel fibers. This raises the possibility that these molecules may act together to create novel specificities from their combined properties.

\footnotetext{
Received Jan. 9, 1998; revised May 18, 1998; accepted June 10, 1998.
}

This work was supported by a grant from the Association Française contre les Myopathies and European Economic Community (EEC) Grants BMH1-CT941378, BH1-CT95-0524, and PL97-0329. M.B. is supported by a Human Capital and Mobility training grant from EEC. We thank C. Moretti for help with morphometric quantification and confocal microscopy, and G. Gennarini and P. Durbec for helpf ul discussions.

Correspondence should be addressed to Dr. Catherine Faivre-Sarrailh, Laboratoire de Génétique et de Physiologie du Développement, UMR 6545 Centre National de la Recherche Scientifique, Parc Scientifique de Luminy, 13288 Marseille cedex 9, France.

Copyright () 1998 Society for Neuroscience $\quad 0270-6474 / 98 / 186853-18 \$ 05.00 / 0$
A striking example of developmental regulation is the transient expression of TAG-1, which is restricted to the period of axonal elongation during the first 2 postnatal weeks in the mouse (Yamamoto et al., 1990; Bailly et al., 1996). F3 is also strongly expressed at that time but continues to be present in the mature cerebellum on the parallel fibers and their presynaptic varicosities (Faivre-Sarrailh et al., 1992). When used as culture substrate, TAG-1/axonin-1 is able to stimulate neurite outgrowth of spinal and dorsal root ganglia (DRG) neurons (Furley et al., 1990; Kuhn et al., 1991; Stoeckli et al., 1991; Felsenfeld et al., 1994). In contrast, F3 has been shown to exert different effects on axonal elongation depending on the neuronal cell type. F3 expressed at the membrane of transfected Chinese hamster ovary (CHO) cells is able to promote neurite elongation of DRG sensory neurons (Gennarini et al., 1991; Durbec et al., 1992), whereas it inhibits neurite outgrowth of cerebellar granule cells (Buttiglione et al., 1996).

A common characteristic that F3/F11 and TAG-1/axonin-1 share with other molecules of the Ig superfamily is that a single molecule binds to several members of the same family and that such heterophilic interactions may occur both in cis (on the same membrane) or in trans (on opposite membranes) (for review, see Brümmendorf and Rathjen, 1996). For example, F3/F11 and TAG-1/axonin-1 share the ability to interact functionally with both L1/NgCAM and Bravo/Nr-CAM (Kuhn et al., 1991; Brümmendorf et al., 1993; Morales et al., 1993; Olive et al., 1995). 

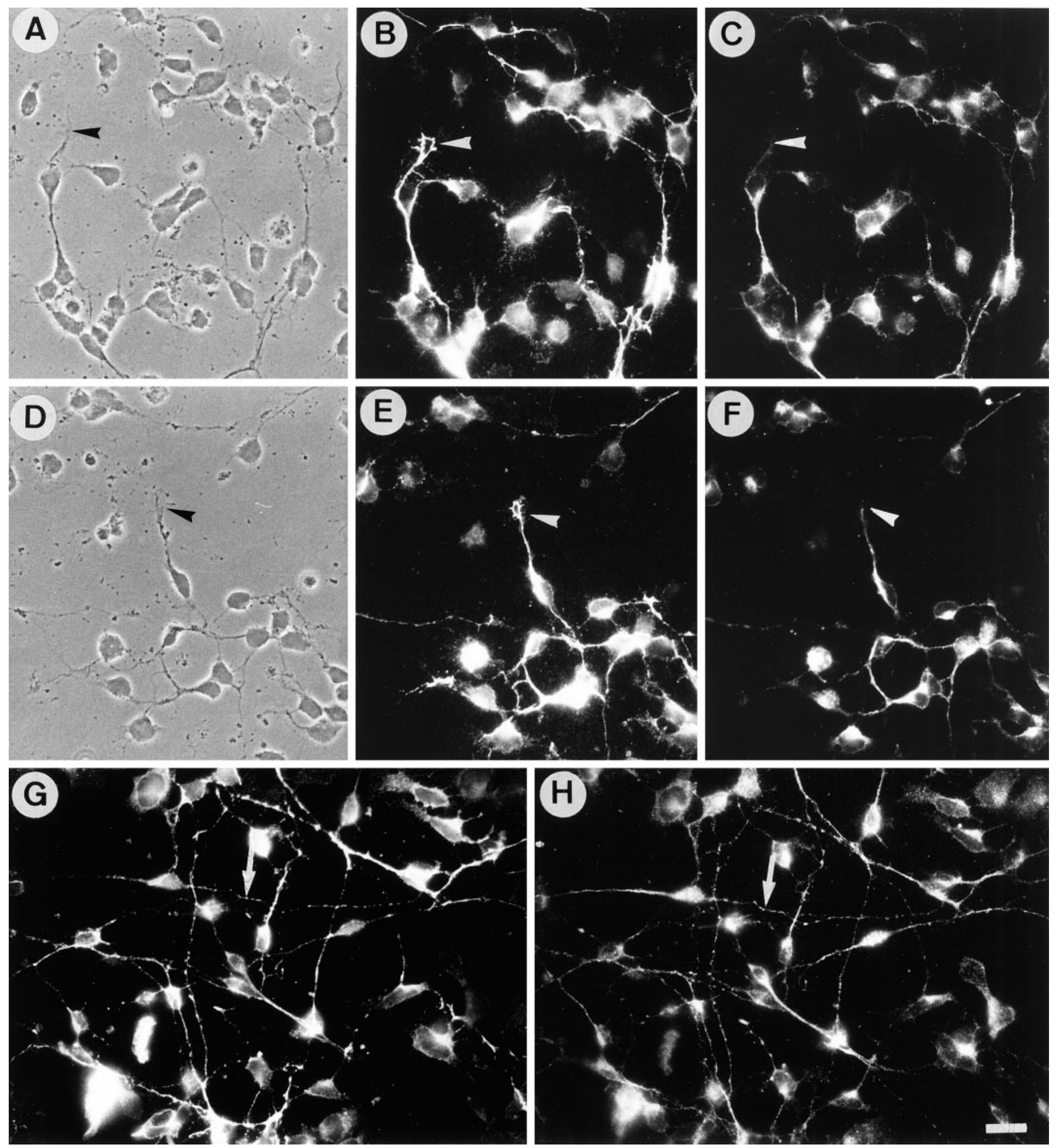

Figure 1. Immunoreactivity for F3 and TAG-1 in neurons from cerebellum. Double-staining immunofluorescence of monoclonal anti-TAG-1 mouse IgM antibody $(B, E, G)$ and anti-F3 antiserum $(C, F, H)$ in primary cerebellar culture after $1 \mathrm{~d}$ in vitro. On poly-L-lysine substrate $(A-F)$, neurites were immunoreactive for F3, especially in their proximal part, whereas growth cones were unlabeled (arrowheads). Growth cones were intensely labeled (arrowheads), and neurites displayed a nonuniform staining for TAG-1. On laminin substrate $(G, H), \mathrm{F} 3$ and TAG-1 immunoreactivities were found to be highly colocalized on neurites (arrows). Scale bar, $10 \mu \mathrm{m}$.

These complex interactions may have functional implications when Ig subfamily molecules are coexpressed, as in the case of developing parallel fibers. To test for the effects of coexpression, we have designed a model system in vitro. By presenting TAG-1 and F3 to granule cells either separately or together on the surface of transfected $\mathrm{CHO}$ cells, we demonstrate an antagonistic effect of TAG-1 and F3 on neurite outgrowth and investigate the mechanisms that could account for this functional interaction. 
CHO
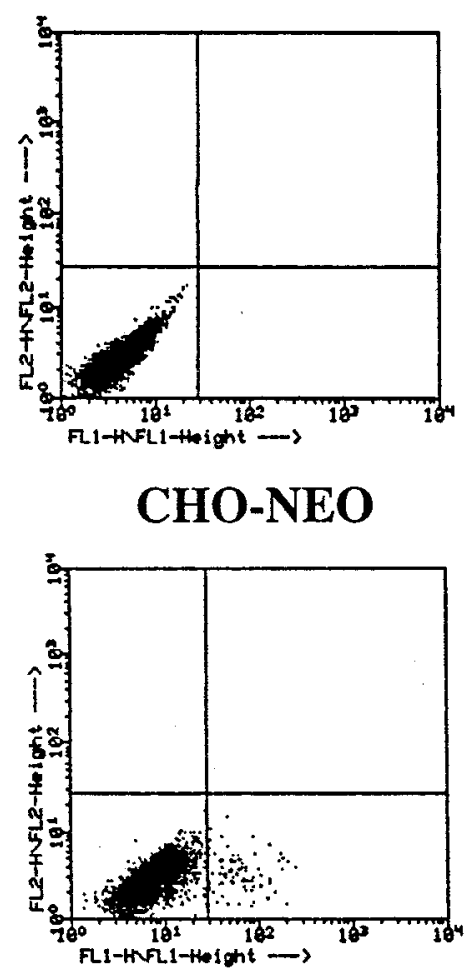

TAG-1
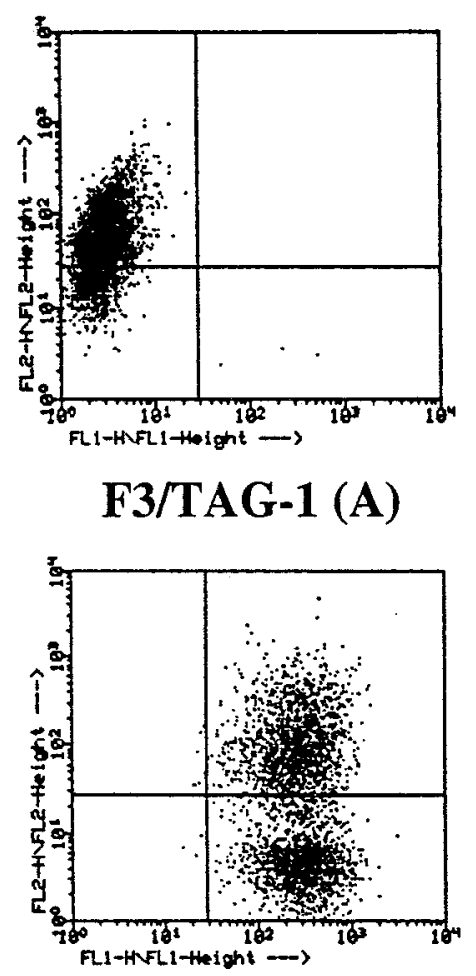

F3

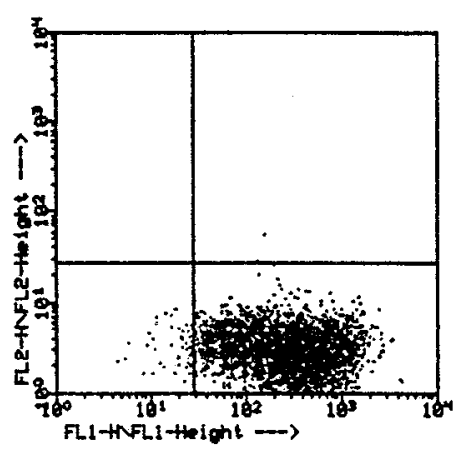

F3/TAG-1 (B)

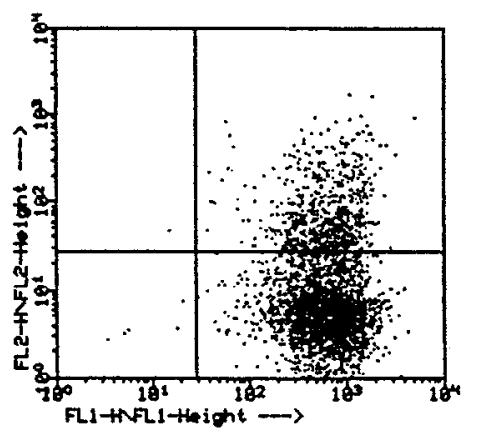

Figure 2. Cell surface expression of F3 and TAG-1 molecules on CHO transfected cells analyzed by flow cytometric fluorescence. The two-dimensional dot plot representation of the relative fluorescence intensity is given in logarithmic scale ( $x$-axis, F3 fluorescence; $y$-axis, TAG-1 fluorescence). Control $\mathrm{CHO}$ cells and the cell line transfected with pRc/CMV plasmid (CHO-NEO) were entirely negative for F3 and TAG-1. Quantification data indicated that $>95 \%$ of F3-transfected cells were positive for F3 and $80 \%$ of transfected CHO TAG-1 cells were positive for TAG-1. The double transfectants, F3/TAG-1-A and F3/TAG-1-B, contained 50 and 30\% of cells positive for TAG-1, respectively; >95\% of cells were positive for F3 in both clones.

\section{MATERIALS AND METHODS}

\section{Antibodies}

Anti-GAP-43 antiserum was a gift from Dr. Graham Wilkin (Imperial College, London). The mouse monoclonal anti-GFAP was purchased from Sigma (St. Louis, MO), and the mouse monoclonal antiphosphorylated neurofilament antibody (SMI-31) from was from Sternberger Monoclonals. Anti-N-CAM antiserum was prepared in our laboratory as described previously (Rougon and Marshak, 1986). For the F3 immunofluorescence study on neurons, the designated anti-D1-1 rabbit antiserum directed against the hinge domain of F3 expressed as a fusion protein was used (Gennarini et al., 1989). For FACSscan analysis and confocal microscopy on $\mathrm{CHO}$ cells and Western blot, a rabbit antiserum prepared against the F3 Ig-like domains expressed as a fusion protein in Escherichia coli was used and designated 24 (Gennarini et al., 1991). A mouse IgM monoclonal anti-TAG-1 antibody 4D7 (Yamamoto et al., 1990) (ascite fluid) was used for immunofluorescence study on neurons and antibody-mediated cross-linking on CHO cells. Immunoprecipitation and Western blot were performed with a rabbit anti-TAG-1 antiserum (named TG3) or monoclonal anti-TAG-1 antibody 4D7. Peroxidase-, FITC- and Texas Red-conjugated Igs were purchased from Jackson ImmunoResearch (Immunotech, Marseille, France).

\section{Cell cultures}

All of the cell culture media, fetal calf serum (FCS), and horse serum were purchased from Life Technologies (Gaithersburg, MD).

Recombinant $\mathrm{CHO}$ cell lines. The CHO cell line LR-73 was maintained in DMEM supplemented with $10 \%$ FCS, $50 \mathrm{U} / \mathrm{ml}$ penicillin, and 50 $\mu \mathrm{g} / \mathrm{ml}$ streptomycin. The F3-transfected $\mathrm{CHO}$ cell line (1A) was described previously (Durbec et al., 1994). Stable TAG-1-expressing CHO clone was obtained by transfection of $4 \mu \mathrm{g}$ pC-TAG and $400 \mathrm{ng} \mathrm{pRc} /$ CMV (Invitrogen, San Diego, CA) using lipofectamin (Life Technologies) and selection with G418. pC-TAG consists of the entire coding region of a rat TAG-1 (Furley et al., 1990) cloned into the vector
pcDNAI-Amp (Invitrogen). Stable CHO cell lines coexpressing TAG-1 and $\mathrm{F} 3$ were obtained by transfection of the $1 \mathrm{~A} \mathrm{~F} 3$-transfected clone with $4 \mu \mathrm{g}$ of pC-TAG-1 together with $200 \mathrm{ng}$ of pSV2gpt using selection with $0.5 \mathrm{mg} / \mathrm{ml}$ mycophenolic acid in $0.25 \mathrm{mg} / \mathrm{ml}$ xanthine and $15 \mu \mathrm{g} / \mathrm{ml}$ hypoxanthine medium. Isolated cell lines obtained by limiting dilution were analyzed by immunofluorescence and FACSscan analysis.

Cerebellar cell cultures. Dissociated cell cultures were obtained from Swiss mouse cerebella on postnatal day 5. Cells were dissociated by combined trituration and trypsinization, and grown in chemically defined medium DMEM/Ham's F-12 (3:1 v/v) containing $0.2 \mathrm{~mm}$ glutamine, 5 $\mu \mathrm{g} / \mathrm{ml}$ insulin, $100 \mu \mathrm{g} / \mathrm{ml}$ transferrin, $20 \mathrm{~nm}$ progesterone, $100 \mathrm{~mm}$ putrescine, $30 \mathrm{~nm}$ selenium, $100 \mathrm{U} / \mathrm{ml}$ penicillin, and $0.1 \mathrm{mg} / \mathrm{ml}$ streptomycin. Reaggregate cultures of cerebellar neurons from mouse on postnatal day 5 were prepared according to Buttiglione et al. (1996).

\section{Neurite outgrowth on transfected $\mathrm{CHO}$ cells}

Parental and transfected (CHO-F3, CHO-TAG-1, F3-TAG-1-A, F3TAG-1-B) CHO cells were seeded in eight-well labtek slides at a density of $8 \times 10^{4}$ cells/well. Cells were grown for $24 \mathrm{hr}$ until confluency and used as monolayer underlying dissociated or aggregated neurons. Cocultures were established by adding either $10^{4}$ dissociated cerebellar neurons or $\sim 50$ cerebellar cell aggregates and maintained for $18 \mathrm{hr}$ in defined medium before fixation and immunostaining. The mocktransfected CHO-pRc/CMV cell line (CHO-NEO) gave results similar to the parental $\mathrm{CHO}$ cell line under all the experimental conditions described above. A CHO-F3-pSV2gpt mock cell line was used as control for double transfectants and did not modify neurite outgrowth and fasciculation when compared with CHO-F3 cells.

Neurite lengths were quantified with a Zeiss Axiophot microscope equipped with epifluorescence and a COHU 4700 camera. Quantification was performed using a custom macro written for Optimas 4.1 software package (Bioscan) and a PC vision plus frame grabber (Imaging Technology). The longest neurite of at least 60 isolated neurons was measured under each experimental condition for each experiment. De- 

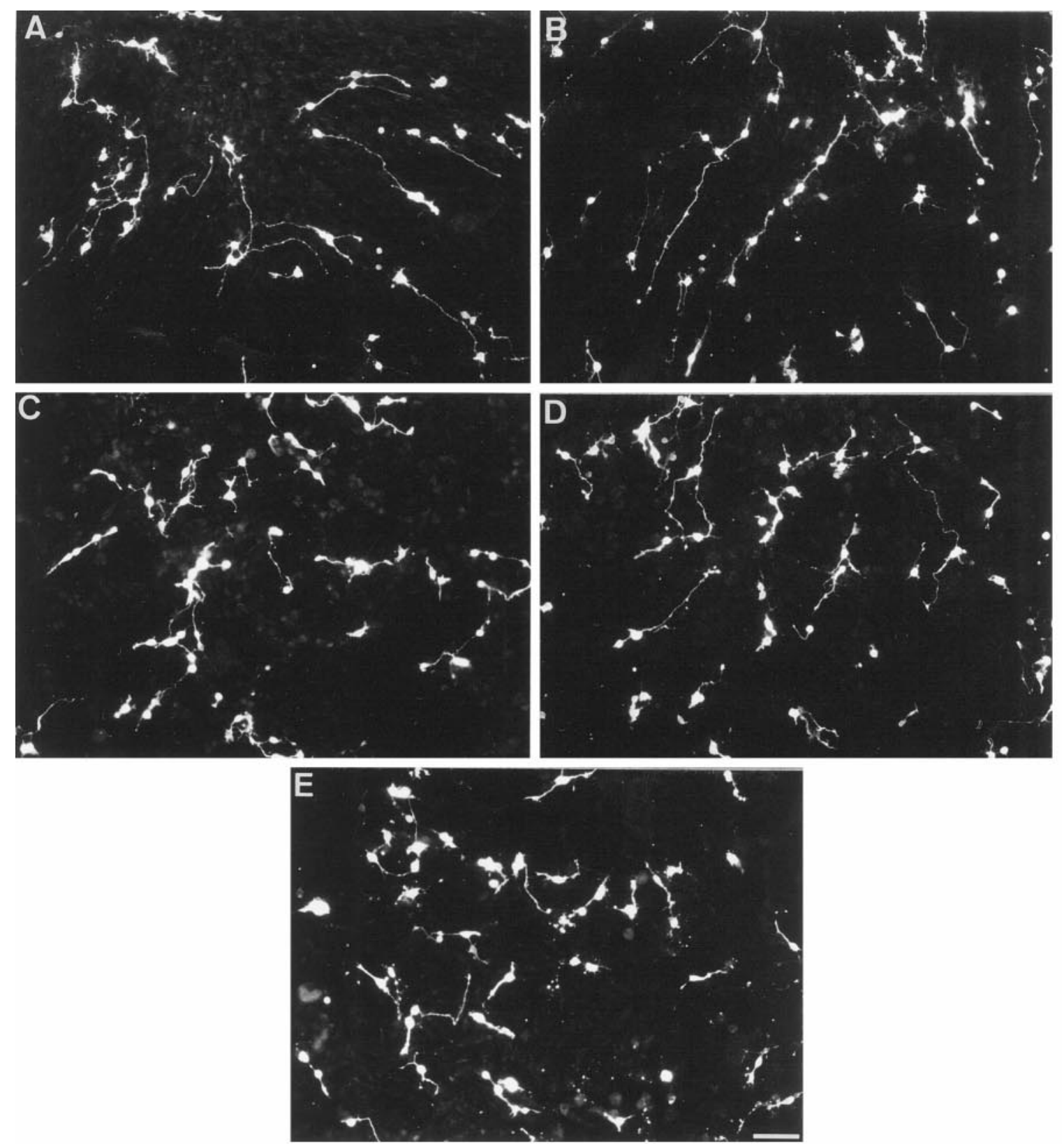

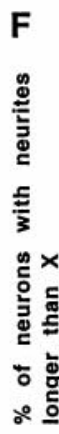

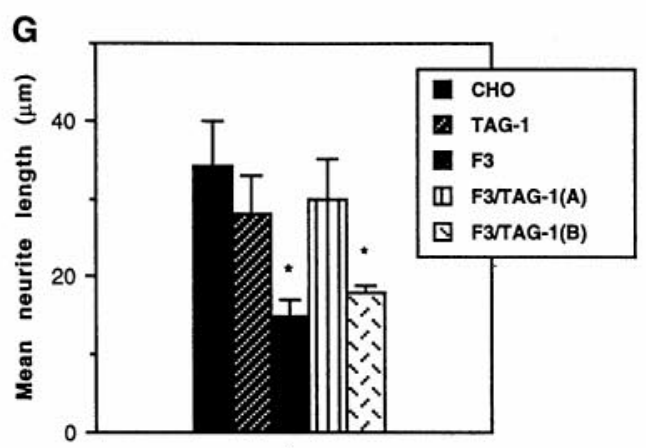

Figure 3. F3-mediated inhibition of neurite outgrowth from cerebellar neurons was prevented by TAG-1. Morphology of cerebellar neurons from postnatal day 5 mice cultured for $18 \mathrm{hr}$ on monolayers of control $(A)$, TAG-1-transfected $(B)$, and F3-transfected $(C)$ CHO cells is shown. Monolayers of double transfectants F3-TAG-1-A $(D)$ and F3-TAG-1-B $(E)$ displaying 50 and 30\% of TAG-1-positive cells, respectively, are shown. Note that the number of cerebellar neurons on the different layers was approximately the same and that neurites were shorter in $C$ and $E$ (Figure legend continues) 
fasciculation of neurites from cerebellar neuron aggregates was estimated from the number of isolated neurites intersecting transects perpendicular to the neuritic halo as shown in the diagram in Figure $6 B$. Digitalization of images was performed at $250 \times$ magnification, and integrated profiles were obtained using a Visiolab software (Biocom). The width and fluorescent intensity of neurites or bundle of neurites were estimated. Isolated neurites were defined as displaying an apparent caliber $<6$ pixels $(\sim 2 \mu \mathrm{m})$ and gray-level intensity $<120$.

\section{Indirect immunofluorescence}

For the visualization of neurons grown on monolayers, cells were fixed with $4 \%$ paraformaldehyde in PBS for $15 \mathrm{~min}$, permeabilized with methanol for 10 min, rehydrated in PBS, incubated with anti-GAP-43 antiserum (diluted 1:500) in PBS containing 3\% bovine serum albumin (BSA) for $1 \mathrm{hr}$, rinsed with PBS, and incubated with Texas Redconjugated anti-rabbit Igs (diluted 1:100) in PBS containing 3\% BSA for $1 \mathrm{hr}$. After washing with PBS, cells were mounted in Mowiol (Calbiochem, La Jolla, CA). For double-staining with anti-GFAP monoclonal antibody (diluted 1:1000) and anti-GAP-43 antiserum, cells were processed as indicated above with the additional use of FITC-conjugated anti-mouse Igs (diluted 1:100). The double-staining with anti-TAG-1 monoclonal antibody and anti-GAP-43 antiserum was performed sequentially. Cells fixed with $4 \%$ paraformaldehyde in PBS were processed for anti-TAG-1 immunofluorescence. After permeabilization with $0.1 \%$ Triton X-100 in PBS, anti-GAP-43 immunostaining was performed. F3 and TAG-1 were immunostained in neurons grown on poly-L-lysine coverslips. Cells were fixed with $4 \%$ paraformaldehyde in PBS for 15 min, rinsed with PBS, and incubated for $1 \mathrm{hr}$ with rabbit anti-F3 D1-1 antiserum (1:500) and anti-TAG-1 mouse IgM monoclonal antibody (1:250). After washing with PBS, cells were incubated for $1 \mathrm{hr}$ with FITC-conjugated anti-rabbit $(1: 100)$ and Texas Red-conjugated antimouse IgMs (1:100), rinsed, and mounted in Mowiol.

For flow cytometric fluorescence, CHO cells were harvested in PBS containing $1 \mathrm{~mm}$ EDTA, pelleted, and resuspended in $1 \mathrm{ml}$ of culture medium. Cells were incubated for $30 \mathrm{~min}$ with anti-F3 antiserum 24 $(1: 200)$ and anti-TAG-1 monoclonal antibody (1:250), washed, and incubated with FITC-conjugated anti-rabbit (1:100) and R-phycoerythrinconjugated anti-mouse IgMs $(1: 100)$ and analyzed with FACSscan flow cytometer (Becton Dickinson, Mountain View, CA) lasing at 488 and 578 $\mathrm{nm}$ excitation wavelengths, respectively.

\section{Coupling of recombinant F3-Fc and TAG-1-Fc chimeras to fluorescent microspheres and binding to cultured cells}

The mouse F3 (Gennarini et al., 1989) and TAX-1, the human homolog of TAG-1 (Tsiotra et al., 1993) cDNAs, were fused to the genomic sequence of the $\mathrm{Fc}$ region (hinge, $\mathrm{CH} 2, \mathrm{CH} 3$ ) of the human IgG1 and inserted into the pIG-1 vector. The chimeric proteins called F3-Fc and TAG-1-Fc were transiently expressed into Cos 7 cells after transfection by lipofection (Life Technologies). An MUC18-Fc chimera was kindly provided by Dr. Simmons (Cell Adhesion Laboratory, Oxford, UK) and used as a control. Chimeras were incubated with red or yellow-green fluorescing microspheres [fluospheres, nominal diameter $1 \mu \mathrm{m}$ (Molecular Probes Europe, The Netherlands)] previously conjugated with antihuman Fc Igs. In brief, $50 \mu \mathrm{g}$ of anti-human Fc Ig was added to $5 \times 10^{9}$ fluospheres in $1 \mathrm{ml}$ of PBS for $16 \mathrm{hr}$ at room temperature on a rotating wheel. The fluospheres were centrifuged, resuspended in PBS containing $5 \mathrm{mg} / \mathrm{ml} \mathrm{BSA}$ and $10 \mathrm{mM} \mathrm{NaN}_{3}$ for $30 \mathrm{~min}$ at room temperature, centrifuged, and incubated for $16 \mathrm{hr}$ at $4^{\circ} \mathrm{C}$ with supernatant of Cos cells expressing the F3-Fc or TAG-1-Fc chimera until saturation. The amount of bound chimeric protein was estimated to be $\sim 25 \mu \mathrm{g}$. After washing, fluospheres were stored at $4^{\circ} \mathrm{C}$ in $100 \mu \mathrm{l}$ of PBS containing $5 \mathrm{mg} / \mathrm{ml} \mathrm{BSA}$ and $10 \mathrm{~mm} \mathrm{NaN}_{3}$.

Incubation with protein-conjugated fluospheres (diluted 1:500) was performed for $1 \mathrm{hr}$ at $37^{\circ} \mathrm{C}$ in defined medium on cerebellar cells cultured for $24 \mathrm{hr}$ on poly-L-lysine substrate. To control the specificity of binding, F3 beads were incubated for $1 \mathrm{hr}$ at $4^{\circ} \mathrm{C}$ with anti-F3 $\mathrm{IgG} 24(0.1 \mathrm{mg} / \mathrm{ml})$ before incubation with cerebellar cells. The unbound fluospheres were removed by three washes with defined medium, and cells were fixed for $15 \mathrm{~min}$ at room temperature with $4 \%$ paraformaldehyde and $0.1 \%$ glutaraldehyde in PBS. After permeabilization for 10 min with $0.1 \%$ Triton X-100 in PBS, cells were processed for immunofluorescence staining as described above with mouse monoclonal anti-GFAP antibody (ascites fluid; 1:1000) and mouse monoclonal anti-phosphorylated neurofilament antibody (ascites fluid; 1:1000) used as markers for astrocytes and neurons, respectively, and with FITC-conjugated anti-mouse Igs $(1: 100)$.

Binding experiments with soluble chimeras were performed for $1 \mathrm{hr}$ at $37^{\circ} \mathrm{C}$ on cerebellar cells cultured for $24 \mathrm{hr}$ on poly-L-lysine substrate. The $\mathrm{F} 3-\mathrm{Fc}$ and TAG-1-Fc molecules produced in the culture medium (without FCS) of transfected Cos 7 cells were concentrated to $20 \mu \mathrm{g} / \mathrm{ml}$ and preclustered for $1 \mathrm{hr}$ at $37^{\circ} \mathrm{C}$ with $50 \mu \mathrm{g} / \mathrm{ml}$ anti-human Fc Igs before incubation with neurons.

\section{Antibody-mediated cross-linking}

Double-transfected CHO-F3/TAG-1-A cells were first incubated for $1 \mathrm{hr}$ with mouse IgM anti-TAG-1 monoclonal antibody in culture medium at $4^{\circ} \mathrm{C}$. After washing, cross-linking was induced with Texas Redconjugated anti-mouse IgMs for $30 \mathrm{~min}$ at $37^{\circ} \mathrm{C}$. After washing, cells were immunostained for $\mathrm{F} 3$ and for $\mathrm{N}-\mathrm{CAM}$ using culture medium containing $0.02 \% \mathrm{NaN}_{3}$, washed, and fixed for $1 \mathrm{~min}$ in acetic acid/alcohol (5:95) at $-20^{\circ} \mathrm{C}$. Nonclustered control cells were incubated for $1 \mathrm{hr}$ at $4^{\circ} \mathrm{C}$ and for $30 \mathrm{~min}$ at $37^{\circ} \mathrm{C}$ without antibodies and then were processed for doubleimmunostaining for TAG-1 and F3. Cells were mounted in Mowiol and examined using a confocal laser scanning microscope (Zeiss). Cells were optically sectioned in the $x-y$ plane (parallel to the substratum) using $63 \times$ NA 1.4 objective and minimum slice thickness of $1 \mu \mathrm{m}$, with multiple scan averaging. Simultaneous two-channel recording was performed using excitation wavelengths of $488 / 543 \mathrm{~nm}$, a 515-525 bandpass FITC filter together with a 570 -nm-long pass filter.

\section{Immunoblot and immunoprecipitation analyses of low-density Triton X-100 insoluble complexes from mouse forebrain and of double-transfected $\mathrm{CHO}$ cell line}

Low-density Triton X-100-insoluble complexes were prepared from mouse forebrain as described previously (Olive et al., 1995). Forebrain from mice on postnatal day 1 were dissected and homogenized at $4^{\circ} \mathrm{C}$ by five strokes of a Dounce homogenizer equipped with a Teflon pestle in 20 vol of MES buffer saline $(25 \mathrm{~mm}$ morpholinoethane sulfonic acid, $\mathrm{pH}$ $6.5,0.15 \mathrm{M} \mathrm{NaCl}$ ) containing $1 \%$ Triton X-100 and $1 \mathrm{~mm}$ phenylmethylsulfonyl fluoride (PMSF) as protease inhibitor. The extract adjusted to $40 \%$ sucrose was placed at the bottom of a 5-30\% linear sucrose gradient and centrifuged at $4^{\circ} \mathrm{C}$ for $17 \mathrm{hr}$ at $39,000 \mathrm{rpm}$ in an SW41 Beckman rotor. The opaque band migrating at $10-20 \%$ sucrose density was harvested, diluted in MES buffer saline, and centrifuged at $4^{\circ} \mathrm{C}$ for $1 \mathrm{hr}$ at $45,000 \mathrm{rpm}$ in a Ti50 Beckman rotor. The pellet corresponding to the low-density Triton X-100-insoluble complexes was solubilized in electrophoresis sample buffer and analyzed by $7 \%$ PAGE and compared with an equivalent amount of microsome fraction from mouse brain on postnatal day 1 prepared as described previously (Olive et al., 1995) by immunoblotting for F3, TAG-1, and N-CAM. After blotting on nitrocellulose membrane (Amersham, Arlington Heights, IL) and saturation in PBS containing $3 \%$ BSA, proteins were detected by incubation with rabbit anti-TAG-1 (1:2000), anti-F3 (1:1000), or anti-N-CAM (1:1000) immunosera overnight at $4^{\circ} \mathrm{C}$ and peroxidase-conjugated anti-rabbit Igs (1: $10,000)$ for $1 \mathrm{hr}$ at room temperature. Bound antibodies were revealed using peroxidase substrate kit (Dako, Carpinteria, CA).

The low-density Triton X-100-insoluble complexes from mouse forebrain were homogenized in $1 \%$ Nonidet P-40 (NP-40) and $0.5 \%$ deoxycholate in $50 \mathrm{~mm}$ Tris, $\mathrm{pH} 7.5$, and $\mathrm{NaCl} 150 \mathrm{~mm}$ for $2 \mathrm{hr}$ at $4^{\circ} \mathrm{C}$ and

(but not in $B$ and $D$ ) by comparison with $A$. Neurons were stained for GAP-43 immunoreactivity. Scale bar, $50 \mu \mathrm{m} . F$, Cumulative neurite length histogram showing the distribution of neurite lengths in a representative experiment. Distribution was plotted as percentage of neurons with longest neurite ( $y$-axis) longer than a given length ( $x$-axis). $G$, Mean length of the longest neurite. Measurements were taken on $>60$ neurons under each experimental condition. Mean values \pm SEM from three independent experiments. *Significant difference $(p<0.05)$ with control CHO cells using ANOVA followed by Fischer's PLSD test. 

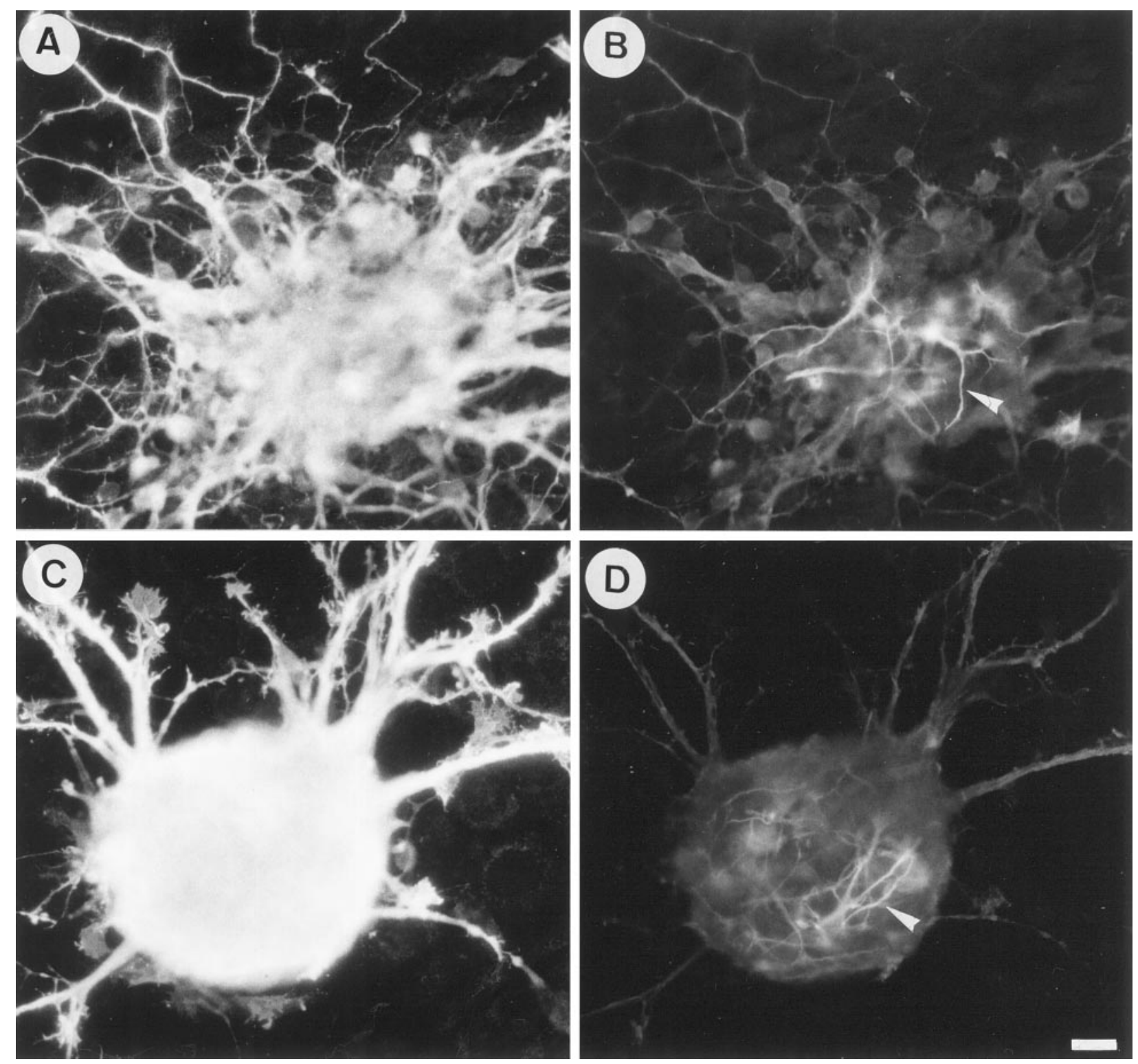

Figure 4. The neurite fasciculation induced on F3-expressing $\mathrm{CHO}$ cells did not depend on neuron-astrocyte interaction. Double-staining immunofluorescence of anti-GAP-43 rabbit antiserum $(A, C)$ and anti-GFAP monoclonal antibody $(B, D)$ in granule cell aggregates grown onto CHO $(A, B)$ and CHO-F3 $(C, D)$ monolayers is shown. Note that few GFAP-positive astrocytes were localized in the central region of the aggregates, whereas no immunostaining for GFAP was detected along the neuritic halo. Scale bar, $10 \mu \mathrm{m}$.

centrifuged at $15,000 \times g$ for $15 \mathrm{~min}$ at $4^{\circ} \mathrm{C}$. After preclearing for $4 \mathrm{hr}$ at $4^{\circ} \mathrm{C}$ with protein A-Sepharose, samples were immunoprecipitated with rabbit anti-TAG-1 immune or preimmune serum $(5 \mu \mathrm{l})$ on protein A preformed complex for $16 \mathrm{hr}$ at $4^{\circ} \mathrm{C}$. The beads were washed as described above, and immunoprecipitates were analyzed on immunoblot with antiTAG-1, anti-F3, and anti-N-CAM antibodies as described above.

Double-transfected F3-TAG-1-A CHO cells were harvested in PBS containing $1 \mathrm{~mm}$ EDTA, lysed for $10 \mathrm{~min}$ on ice with $50 \mathrm{~mm}$ Tris, $\mathrm{pH}$ 7.5, $1 \% \mathrm{NP}-40,10 \mathrm{~mm} \mathrm{MgCl} 2,1 \mathrm{~mm}$ PMSF, $5 \mu \mathrm{g} / \mathrm{ml} \alpha$-2-macroglobulin, 1 $\mu \mathrm{m} / \mathrm{ml}$ leupeptin, and $5 \mu \mathrm{g} / \mathrm{ml}$ pepstatin and centrifuged at $4^{\circ} \mathrm{C}$ for 15 $\min$ at $15,000 \times g$. Aliquots of the supernatant were analyzed by immunoblotting with TAG-1, F3, and N-CAM antibodies. After preclearing, the supernatant was immunoprecipitated with monoclonal mouse IgM anti-TAG-1 antibody $(5 \mu \mathrm{l})$, for $16 \mathrm{hr}$ at $4^{\circ} \mathrm{C}$, bound on protein $\mathrm{A}$ previously incubated with rabbit anti-mouse $\operatorname{IgMs}(5 \mu \mathrm{l})$. The beads were washed twice with $50 \mathrm{~mm}$ Tris, $150 \mathrm{~mm} \mathrm{NaCl}$, and $1 \% \mathrm{NP}-40$ and twice with $50 \mathrm{~mm}$ Tris and $150 \mathrm{~mm} \mathrm{NaCl}$, and immunoprecipitate was analyzed by immunoblotting with TAG-1, F3, and N-CAM antibodies.

\section{RESULTS}

\section{Distribution of TAG-1 and F3 on granule cells in vitro}

Dissociated neuronal cell cultures obtained from mouse cerebella on postnatal day 5 are composed of one major cell type, the granule cell. Neurons cultured on poly-L-lysine exhibited numerous growth cones with large lamellipodia (Fig. $1 A-F$ ). As described previously, granule cells showed a nonuniform staining for F3 after $24 \mathrm{hr}$ in vitro (Buttiglione et al., 1996). F3 immunoreactivity was present in a restricted part of the neurites, mostly in their proximal region, and the neuronal growth cones were unlabeled (Fig. 1C,F). A different pattern of expression was observed for TAG-1 because the growth cones were strongly labeled (Fig. 1B,E). However, F3 and TAG-1 were also found colocalized at the surface of neurites or parts of neurites. This colocalization of TAG-1 (Fig. $1 G$ ) and F3 (Fig. $1 H$ ) was observed 

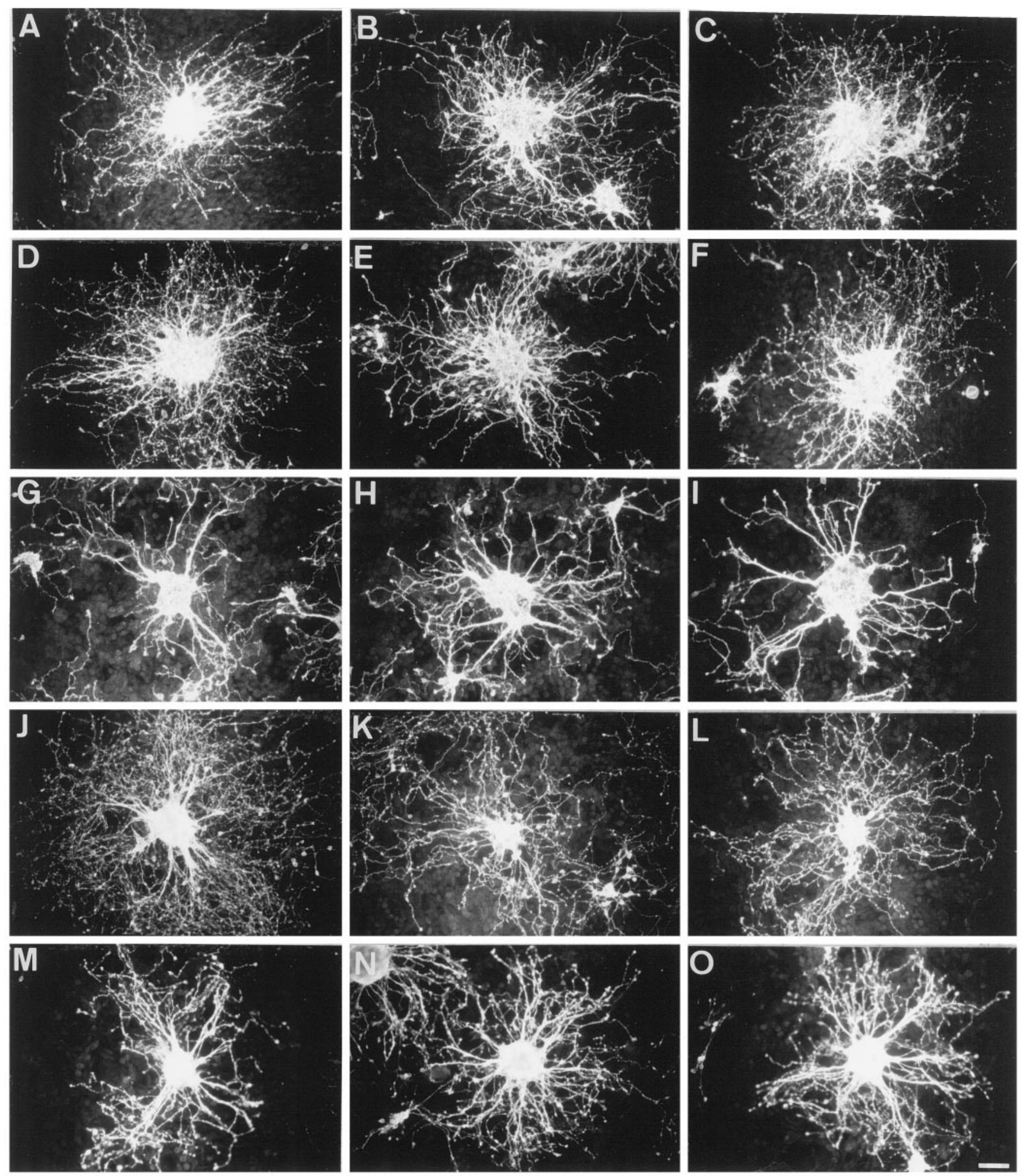

Figure 5. Granule cell aggregates from postnatal day 5 mice cultured for $18 \mathrm{hr}$ on $\mathrm{CHO}$ monolayers. Neurites were defasciculated on control $(A-C)$ and TAG-1-expressing $(D-F)$ cells and highly fasciculated on F3 transfectants $(G-I)$. F3-induced fasciculation was completely prevented in the double-transfected F3-TAG-1-A cells $(J-L)$ and partly reversed in F3-TAG-1-B cells $(M-O)$. Neurons were stained for GAP-43 immunoreactivity. Scale bar, $30 \mu \mathrm{m}$. 
A

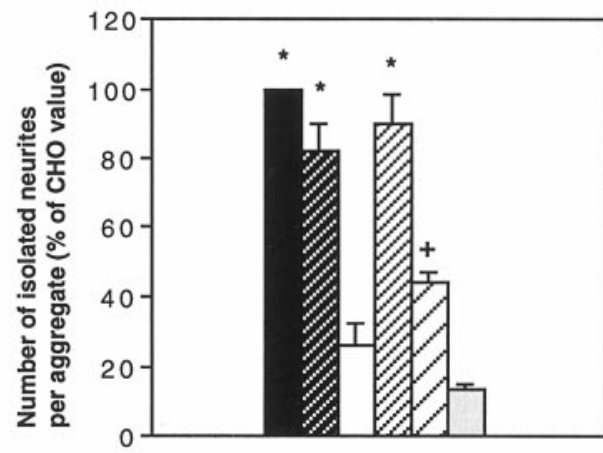

B Quantification of neurite fasciculation

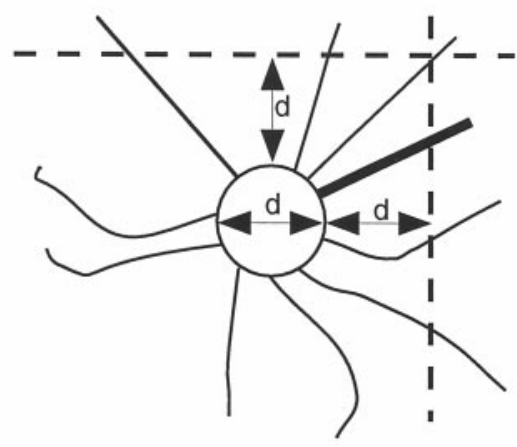

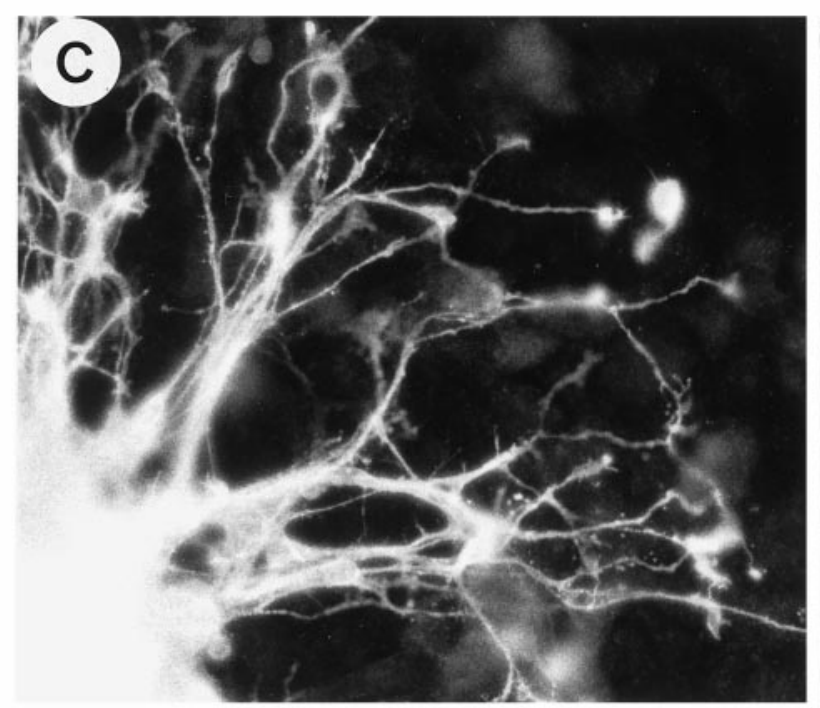
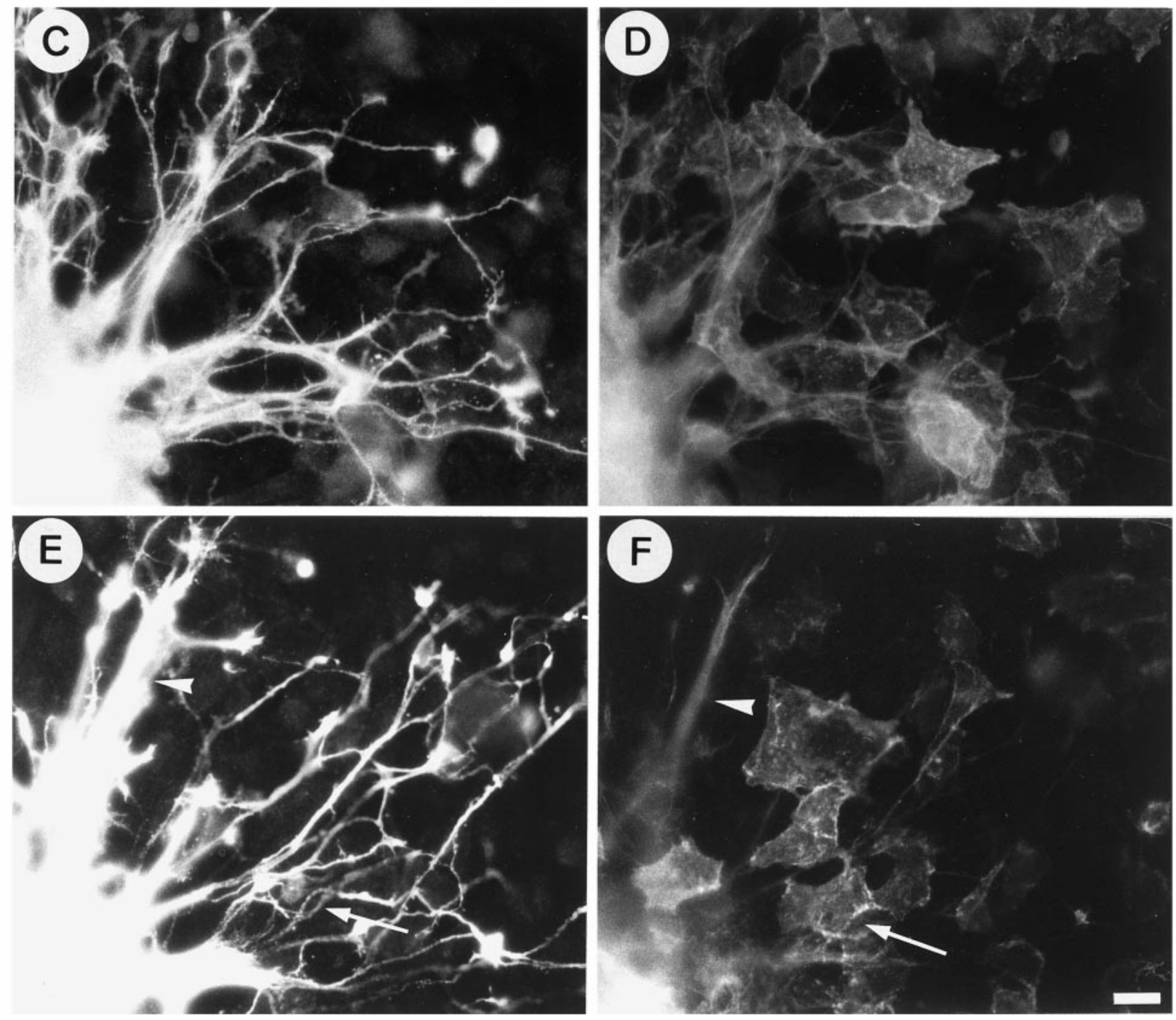

Figure 6. A, F3-mediated fasciculation of neurites from granule cell aggregates was completely prevented in the double-transfected F3-TAG-1-A CHO cells and only partly prevented in the F3-TAG-1-B clone. By contrast, soluble TAG-1-Fc added in the culture medium was unable to block neurite fasciculation induced by CHO-F3 cells. Measurements were taken on six granule cell aggregates under each experimental condition. Means are expressed as percentage of the mean control CHO value \pm SEM. *Significant difference $(p<0.01)$; ${ }^{+}$significant difference $(p<0.05)$ with F3-CHO cells using ANOVA followed by Fischer's PLSD test. $B$, Defasciculation of neurites was estimated as indicated in Material and Methods from the number of isolated neurites intersecting two transects drawn at one diameter $(d)$ distance of the aggregate. The mean diameter of the (Figure legend continues) 
even more frequently when neurons were grown on laminin and displayed long neurites after $1 \mathrm{~d}$ in vitro (Fig. 1G,H, arrows).

\section{TAG-1-expressing $\mathrm{CHO}$ cells did not influence neurite outgrowth of cerebellar granule cells}

We have previously analyzed the function of F3 presented as a membrane component of CHO-transfected cells using an in vitro system of cerebellar granule cells cultured on monolayers of $\mathrm{CHO}$ cells (Buttiglione et al., 1996). To compare F3 and TAG-1 effects under the same experimental conditions, TAG-1 was stably transfected in CHO cells. Clones expressing TAG-1 on their cell surface were obtained by G418 selection and limited dilution cloning. No clone was isolated in which $100 \%$ of cells were positive for TAG-1 at their cell surface, even after subcloning of primary clones. One clone exhibiting $80 \%$ of TAG-1-positive cells, as estimated using flow cytometric fluorescence (Fig. 2) and immunofluorescence staining (data not shown), was selected for the present study and named CHO-TAG- 1 . When used as a monolayer for dissociated culture of DRG, this clone strongly stimulated neurite outgrowth from sensory neurons by comparison with control $\mathrm{CHO}$ cells (data not shown) in accordance with Furley et al. (1990).

Dissociated cerebellar neurons from postnatal day 5 mice were plated at low density onto monolayers of $\mathrm{CHO}$ cells. After $18 \mathrm{hr}$ in vitro, the number of neurons was estimated in randomly selected areas of $0.25 \mathrm{~mm}^{2}$ and was not significantly different on control $(54 \pm 8)$ and TAG-1-expressing $(56 \pm 10)$ CHO cells, indicating that TAG-1 had no effect on cell attachment or survival (Fig. 3). The TAG-1-transfected cells did not modify neurite length of cerebellar neurons when compared with control $\mathrm{CHO}$ cells (Fig. 3B). Quantification of the lengths of the longest neurites showed that their mean size $(28 \mu \mathrm{m})$ was not significantly different from that of neurons grown on $\mathrm{CHO}$ cells $(33 \mu \mathrm{m})$ (Fig. $3 G$ ). By contrast, F3-expressing $\mathrm{CHO}$ cells induced a strong reduction of neurite outgrowth from the whole cerebellar neuron population $(15 \mu \mathrm{m})$ (Fig. 3C,F, $G$ ).

\section{The F3-mediated inhibition of granule cell neurite outgrowth was prevented by TAG-1}

To test the possible functional interaction between TAG-1 and F3, CHO transfectants expressing both glycoproteins were obtained. The F3-transfected CHO clone 1A (Durbec et al., 1992) was transfected with TAG-1 together with a PSV2-gpt plasmid for selection with mycophenolic acid. Two cell lines designated F3TAG-1A and F3-TAG-1B were selected. They displayed 50 and $30 \%$ TAG-1-positive cells, respectively, as determined using flow cytometric fluorescence (Fig. 2). More than $95 \%$ of the cells in both cell lines were still expressing F3 (Fig. 2).

The TAG-1-F3 double-transfectants were used as monolayers for cerebellar cell culture. The mean neurite length $(30 \mu \mathrm{m})$ of cerebellar neurons grown on F3-TAG-1-A cells did not significantly differ from that of neurons cultured on control $\mathrm{CHO}$ cells (Fig. 3D,F,G). This indicated that the coexpression of TAG-1 with F3 blocked the F3 inhibitory effect on neurite outgrowth from the whole cerebellar neuron population. The F3-dependent inhibition of neurite outgrowth was totally prevented with the F3-TAG-1A cell line exhibiting 50\% of TAG-1-positive cells, but not with the F3-TAG-1-B cell line exhibiting only $30 \%$ of TAG1-positive cells. This last cell line induced a significant reduction of the mean neurite length $(18 \mu \mathrm{m})$ by comparison with control CHO cells (Fig. 3E, G).

\section{The F3-induced fasciculation of granule cell neurites was reversed by TAG-1}

To test the functional interaction between TAG-1 and F3 on neurite fasciculation, we used aggregates of granule cells as another model of coculture. These aggregates, obtained according to Gao et al. (1995) and Buttiglione et al. (1996), are composed mainly of granule cells and are virtually devoid of astrocytes (Fig. 4 ), and they will hereafter be termed granule cell aggregates. The CHO-TAG-1 cell line did not significantly modify the defasciculated feature of neurites from granule cell aggregates by comparison with control $\mathrm{CHO}$ monolayer (Figs. 5D-F, 6A). By contrast, F3 expressed at the membrane of $\mathrm{CHO}$ cells induced intense neurite fasciculation (Fig. 5G-I) (Buttiglione et al., 1996). The number of defasciculated neurites grown from granule cell aggregates was estimated as indicated in the diagram (Fig. 6B). It significantly decreased by $74 \%$ on F3-transfected cells by comparison with control $\mathrm{CHO}$ cells (Fig. 6A). As already discussed, inhibition of neurite elongation and fasciculation are probably two aspects of a cellular response that results from F3 molecular interaction (Buttiglione et al., 1996). As shown in Figure 4, only a few GFAP-positive astrocytes were observed in the central region of the granule cell aggregates double-labeled with antiGAP-43, thus demonstrating that glial processes did not interfere with the neurite fasciculation induced on the CHO-F3 monolayer.

A strong defasciculating effect was observed on the F3-TAG1-A cell line (Fig. 5J-L), and the number of isolated neurites increased by $250 \%$ by comparison with $\mathrm{F} 3$-expressing $\mathrm{CHO}$ (Fig. $6 A$ ). A slight but significant defasciculation occurred on the F3-TAG-1-B cell line (Fig. 5M-O), and isolated neurite number increased by $65 \%$ by comparison with $\mathrm{F} 3$-expressing $\mathrm{CHO}$ (Fig. $6 A)$. Thus, the extent of neurite defasciculation correlated with the percentage (50 and 30\%, respectively) of F3-transfected cells coexpressing the TAG-1 molecule. Moreover, double-staining experiments were performed to visualize granule cell axons labeled with anti-GAP-43 grown onto the TAG-1-positive cells among the double-transfected $\mathrm{CHO}$ monolayers. As shown in Figure $6 C, D$ for the F3-TAG-1-A cell line, neurites grown on TAG-1-expressing cells appeared to be defasciculated. The F3TAG-1-B monolayer exhibited a lower proportion of TAG-1positive cells than the F3-TAG-1-A monolayer (Fig. 6, compare $D, F)$. We observed that large fascicles of neurites were present on cells expressing only F3 (Fig. 6E,F, arrowheads), whereas defasciculated processes had elongated on TAG-1-positive CHO-F3 cells.

\section{F3 and TAG-1 binding on growth cones of cerebellar granule cells}

Several explanations can be proposed to explain the antagonist effects of TAG-1 and F3 on neurite growth and fasciculation. One possibility is that they may compete for the same receptor on the neuronal membrane. This possibility was tested by exploring whether soluble TAG-1-Fc added to the culture medium of F3-

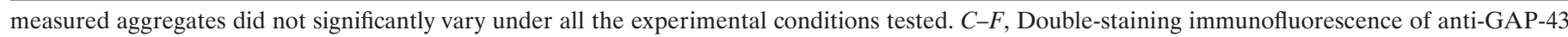

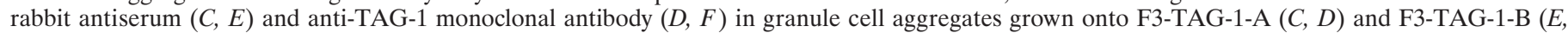

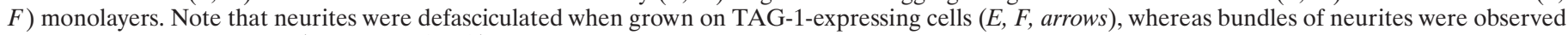
on F3-only expressing cells (E, F, arrowheads). Scale bar, $10 \mu \mathrm{m}$. 

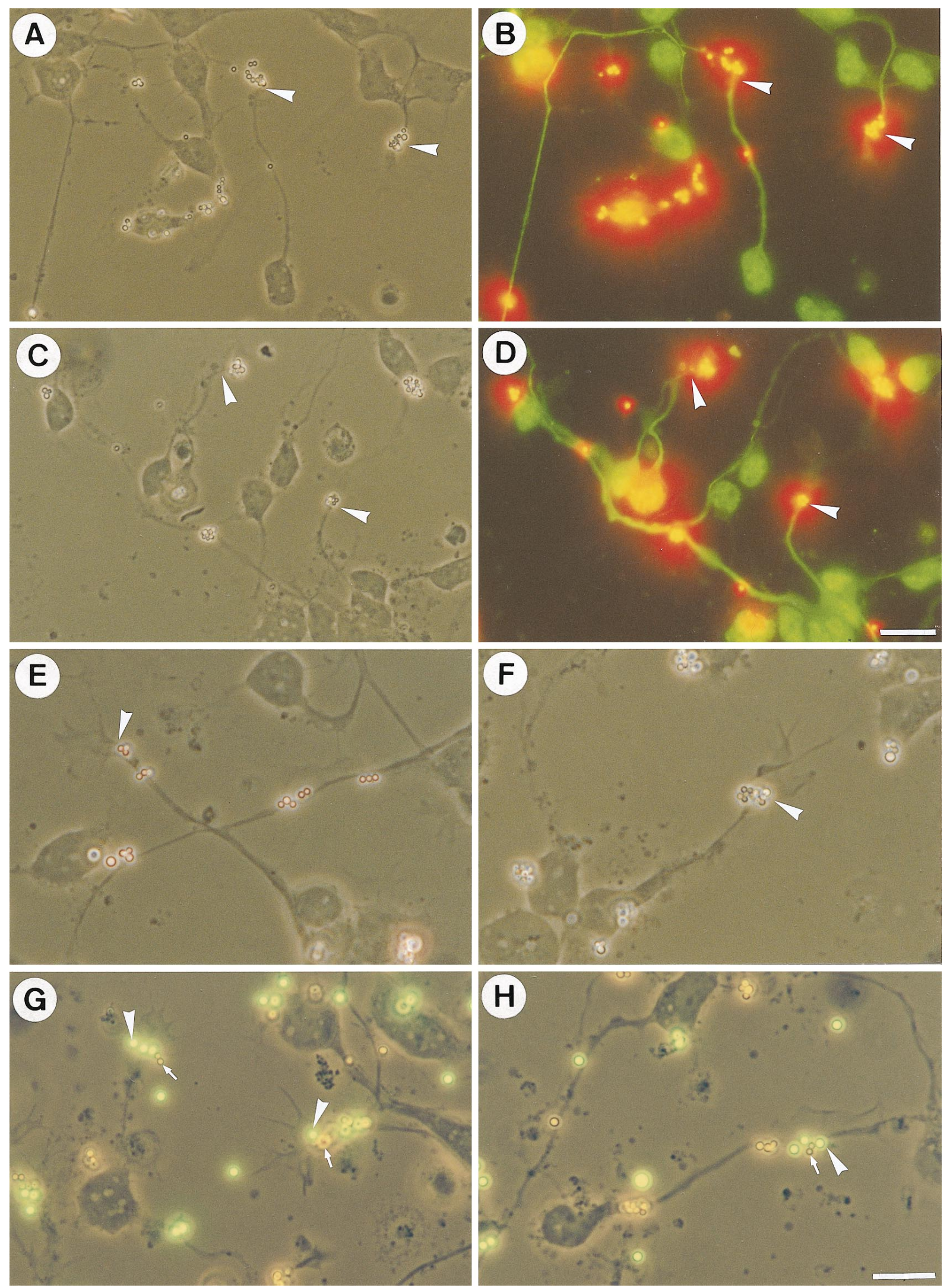

Figure 7. Binding of coated F3-Fc and TAG-1-Fc fluospheres on primary culture of cerebellum. Dissociated cerebellar cells were cultured for $1 \mathrm{~d}$ and incubated for $1 \mathrm{hr}$ with red fluorescent fluospheres conjugated with anti-human Fc antibodies and F3-Fc $(A, B, E)$ or TAG-1-Fc $(C, D, F)$ chimeras. Neurons were identified by immunofluorescence using anti-phosphorylated neurofilament, which labels axons and FITC-conjugated secondary antibodies $(B, D)$, and fluosphere binding was observed in more detail in corresponding phase-contrast images $(A$, $C)$. Neuronal binding sites for both F3-Fc and TAG-1-Fc were localized at the tips of axons $(A-D$, arrows) and occasionally on neurites. Representative neuronal (Figure legend continues) 
transfected CHO cells reproduced the effect observed with F3TAG-1 double transfectants. The recombinant TAG-1-Fc molecules produced in the culture medium of transfected Cos 7 cells were added at a $20 \mu \mathrm{g} / \mathrm{ml}$ concentration either under their soluble dimeric form or preclustered with anti-human $\mathrm{Fc}$ antibodies for 1 $\mathrm{hr}$ at $37^{\circ} \mathrm{C}$. This concentration represented $\sim 50$-fold the concentration of TAG-1 expressed in the double transfectants as estimated using immunoblot. Both the soluble and clustered chimeras were unable to block the F3-induced effects on neurite outgrowth inhibition and fasciculation (Fig. 6A). As a control for the integrity of the molecule, the purified TAG-1-Fc molecule was able to promote neurite elongation from embryonic DRG neurons when coated as a culture substrate (data not shown).

The other possibility is that TAG-1 and F3 bind to individual neuronal receptors. To identify binding sites for F3 and TAG-1 on granule cell neurons, primary cerebellar cultures were incubated with fluospheres carrying F3-Fc and TAG-1-Fc chimeras $\left(10^{8}\right.$ beads $\left./ \mathrm{ml}\right)$. The chimeras produced in the culture medium of Cos-transfected cells were bound to anti-human Fc antibodyconjugated red or green fluospheres. Cerebellar neurons cultured for $1 \mathrm{~d}$ on poly-L-lysine were used for binding experiments because they displayed clearly identifiable lamellipodial growth cones. Binding of F3 and TAG-1 beads applied separately were observed on 72 and $60 \%$ of the total neurons, respectively, identified by labeling with anti-neurofilament antibody (see Fig. $8 A, B)$. The $\mathrm{F} 3$ and TAG-1 fluospheres did not display uniform binding on neurons. Few beads were observed on neurites, whereas there were numerous at the tip of growing neurites (Fig. $7 B, D$, arrows). Quantitative analyses indicated that F3 and TAG-1 beads were present on the growth cones of 28 and $35 \%$ of total cerebellar neurons, respectively (Fig. $8 D$ ). In most cases, binding was restricted to the base of the neuronal growth cones (Fig. $7 E, F)$. Preliminary observations using videomicroscopy indicated that after binding the beads moved within 30-60 sec from the leading edge toward the proximal part of the growth cone where they accumulated in clusters $15-20 \mathrm{~min}$ after addition of the beads (C. Faivre-Sarrailh, unpublished results). This suggests a coupling of F3 receptors with the retrograde F-actin flow (Lin and Forsher, 1995).

To test whether the binding sites for F3 and TAG-1 colocalized on neuronal growth cones, cerebellar granule cells were incubated simultaneously with TAG-1 red microspheres and F3 green microspheres. As exemplified in Figure $7 G, H$, numerous growth cones bound both TAG-1 and F3. As shown in Figure $8 F$, a large proportion of growth cones displayed binding sites for both TAG-1 and F3, and only a few neurons exhibited binding sites restricted to a single type of beads. Therefore, most of the granule cells can be considered as a homogeneous population with regard to their ability to bind both TAG-1 and F3. We did not observe any difference in the binding of TAG-1- and F3conjugated microspheres when neurons were incubated either simultaneously or independently with the beads. Similar percentages of neurons exhibiting F3 (38 vs 28\%) or TAG-1 (34 vs 35\%) binding on their growth cone were observed whatever the experimental condition (Fig. 8, compare E,D).

The specificity of the binding was checked using fluospheres carrying an MUC18-Fc chimera. MUC18 is a molecule of the Ig superfamily not expressed in the nervous system (Lehmann et al., 1989). This chimera did not display any binding to primary culture of cerebellum (data not shown). Moreover, preincubation of F3 fluospheres with anti-F3 IgG prevented binding of the microspheres to the cerebellar neurons (Fig. 8G,H). In addition, GFAP-positive astrocytes exhibited strong binding for F3 but no binding for TAG-1 fluospheres (data not shown). The possibility that the TAG-1- and F3-conjugated microspheres associate before their binding to neurons has to be excluded because the beads that were co-incubated in vitro did not form mixed aggregates. An aggregation assay was performed with F3-Fc and TAG1 -Fc fluospheres $\left(10^{10}\right.$ beads of each species $\left./ \mathrm{ml}\right)$ co-incubated for $1 \mathrm{hr}$ at room temperature. As analyzed using a fluorescence microscope, TAG-1-coated fluospheres did not form mixed aggregates with F3-coated fluospheres, whereas TAG-1 fluospheres displayed self-aggregation (data not shown), in agreement with the reported homophilic binding of TAG-1 (Felsenfeld et al., 1994; Tsiotra et al., 1996). The possibility that the TAG-1 receptor on neurons was TAG-1 itself was also excluded. Neurons were incubated with phosphatidyl inositol-phospholipase C (PI-PLC) $(0.2 \mathrm{U} / \mathrm{ml})$ for $1 \mathrm{hr}$ at $37^{\circ} \mathrm{C}$ to remove glycan phosphatidyl inositol (GPI)-anchored molecules from the cell surface. As analyzed by immunofluorescence, the enzymatic treatment entirely removed labeling for TAG-1 on neurons but did not prevent the binding of TAG-1 fluospheres (Fig. 8C).

Steric constraints imposed by the size of beads might prevent revelation of all the binding sites for the Fc chimeras. Hence, we also examined binding sites for TAG-1 and F3 using soluble or clustered chimeras prepared as above. Soluble chimeras did not show detectable binding (data not shown). By contrast, as for coated fluospheres, binding sites for F3-Fc revealed by indirect immunofluorescence were present on both astrocytes (data not shown) and neurons (Fig. 9A,B), whereas binding for TAG-1-Fc was restricted to neurons (Fig. $9 C, D$ ). Thus, binding experiments with clustered chimeras confirmed that growth cones are enriched in receptors for both TAG-1 and F3 (Fig. 9). In addition, this technique also revealed patches of staining on neurites and cell bodies (Fig. 9).

\section{cis-interaction between F3 and TAG-1 in double- transfected $\mathrm{CHO}$ cells}

The antagonistic effects of TAG-1 and F3 in the modulation of neurite outgrowth and fasciculation of cerebellar neurons could also result from interactions between the two molecules taking place in the CHO membrane. The distribution of TAG-1 and F3 at the surface of double-transfected $\mathrm{CHO}$ cells was investigated using immunofluorescent staining.

Under normal conditions, F3 and TAG-1 displayed nonoverlapping punctate distribution on the $\mathrm{CHO}$ membrane as analyzed using double-staining and confocal microscopy (Fig. 10A-D). However, it is possible that TAG-1 and F3 might become associated on the $\mathrm{CHO}$ cell membrane if bound by receptors on the cerebellar neurons. To test this hypothesis, specific antibodies were used to mimic receptor-binding effects, and clustering of TAG-1 in double-transfected $\mathrm{CHO}$ cells was achieved by anti-

\section{$\leftarrow$}

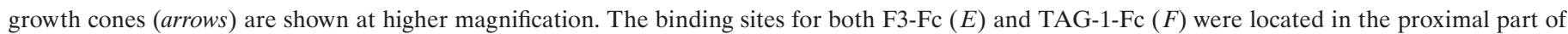

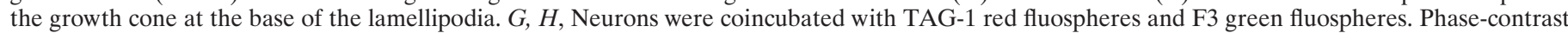

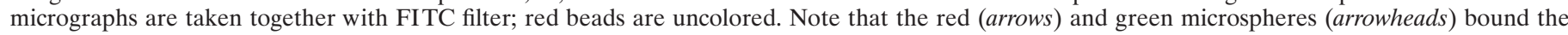
same subdomains of growth cones. Scale bars: $A-D, 10 \mu \mathrm{m} ; E-H, 20 \mu \mathrm{m}$. 
A

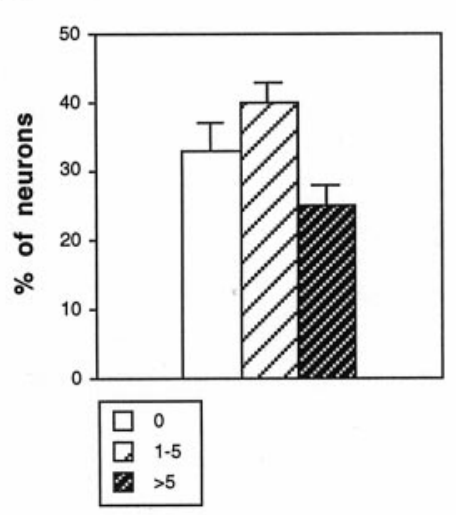

D
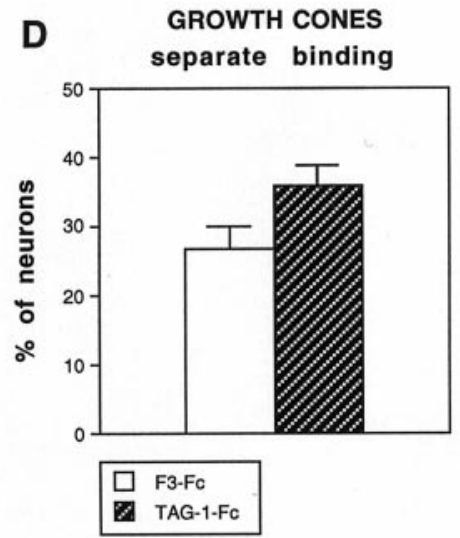

B

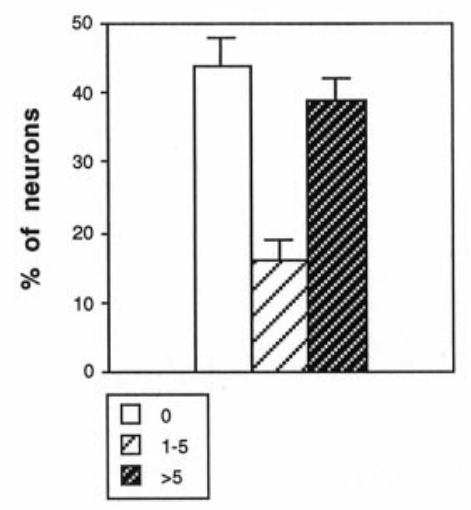

E

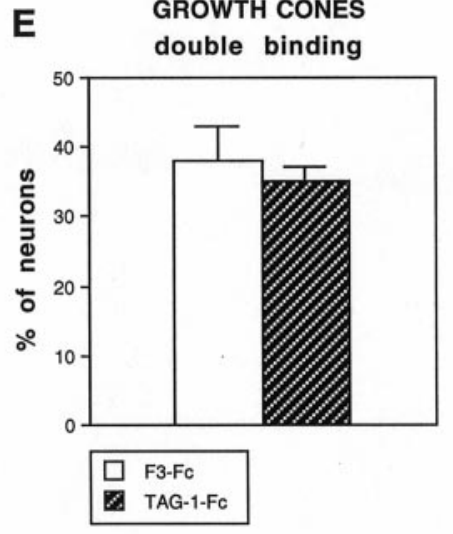

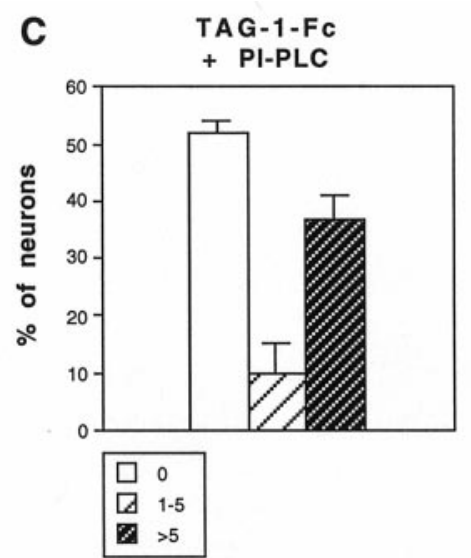

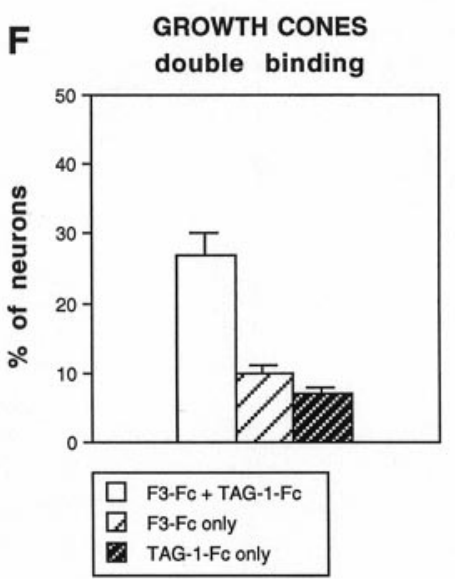

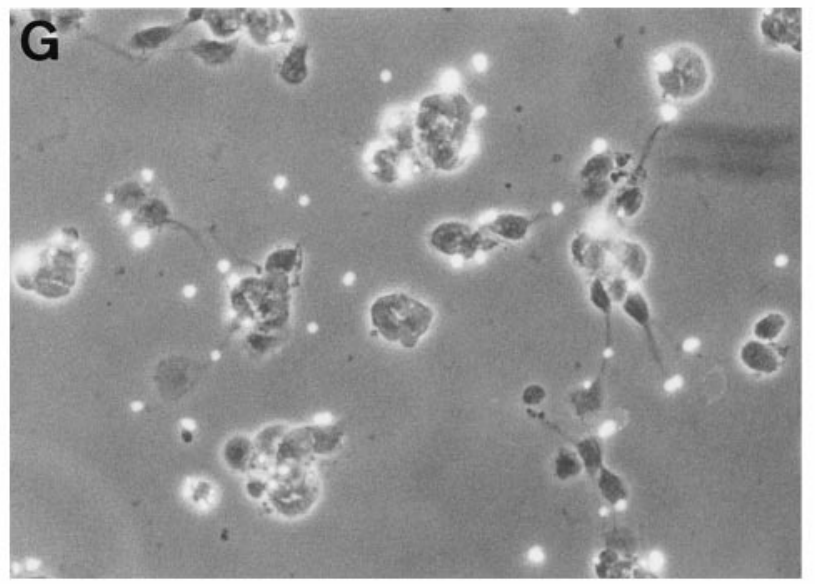

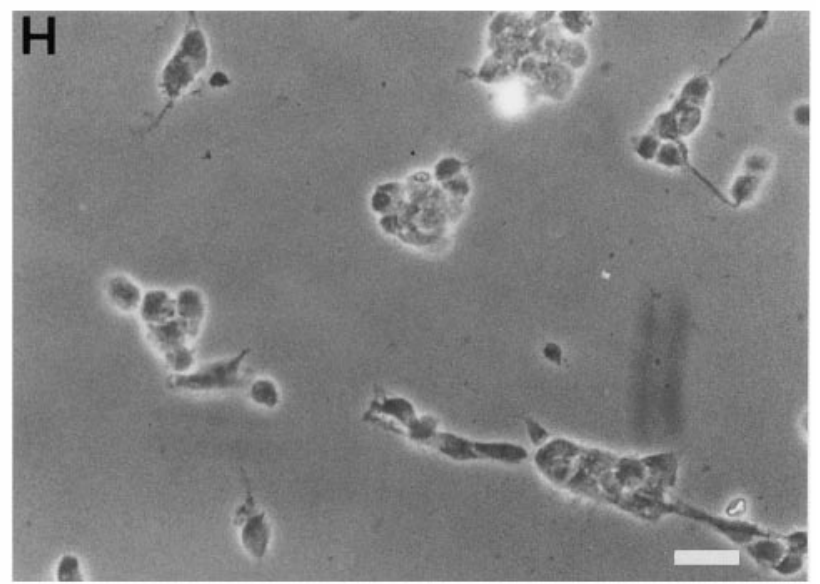

Figure 8. Quantitative analysis of F3-Fc and TAG-1-Fc fluosphere binding on cerebellar neurons. Dissociated cerebellar cells were cultured for $1 \mathrm{~d}$ and incubated for $1 \mathrm{hr}$ with red fluorescent fluospheres conjugated with anti-human Fc antibodies and F3-Fc $(A)$ or TAG-1-Fc $(B, C)$ chimeras. Distribution is shown as percentage of neurons that displayed no bead (0), between 1 and 5 beads $(1-5)$, and more than five beads $(>5)$. $C$, Neurons were incubated with PI-PLC to remove GPI-anchored molecules from the cell surface. Note that TAG-1-Fc microsphere binding was not modified. $D$, $E$, Percentage of neurons that showed more than three beads conjugated with F3-Fc or TAG-1-Fc on their growth cone when beads were incubated separately ( $D$ ) or simultaneously $(E)$. F, Percentage of neurons with double-labeled, F3-Fc only-labeled, and TAG-1-Fc only-labeled growth cones in double-binding experiments. Mean \pm SEM of three independent experiments. More than 120 neurons were analyzed under each experimental condition. $G, H$, F3-Fc microspheres were incubated for $1 \mathrm{hr}$ at $4^{\circ} \mathrm{C}$ with rabbit nonimmune $(G)$ or anti-F3 Igs $(H)$ at a concentration of $0.1 \mathrm{mg} / \mathrm{ml}$ before incubation for $1 \mathrm{hr}$ with cerebellar neurons cultured for $1 \mathrm{~d}$ in vitro. Note that in $H$ the binding of fluorescent F3-Fc beads was almost entirely prevented by preincubation with anti-F3 Igs. Scale bar, $10 \mu \mathrm{m}$. 

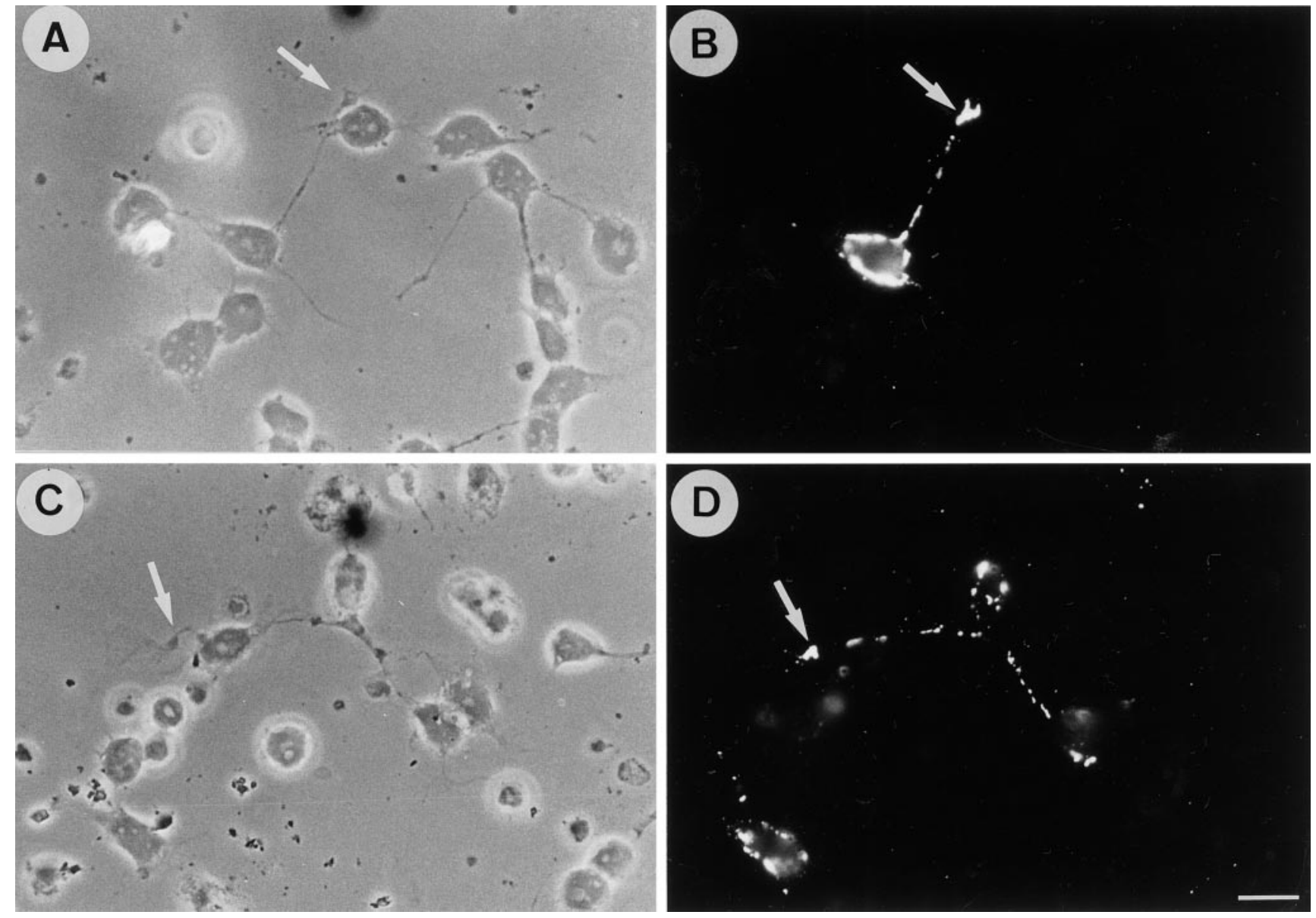

Figure 9. Binding of F3-Fc and TAG-1-Fc chimeras on primary culture of cerebellum. Dissociated cerebellar cells were cultured for $1 \mathrm{~d}$ and incubated for $1 \mathrm{hr}$ with culture medium containing F3-Fc $(A, B)$ and TAG-1-Fc $(C, D)$ chimeras $(20 \mu \mathrm{g} / \mathrm{ml})$ preclustered with anti-human Fc antibodies $(50 \mu \mathrm{g} / \mathrm{ml})$. Neurons displayed binding sites for F3 and TAG-1 on their growth cones (arrows), neurites, and cell bodies. Scale bar, $15 \mu \mathrm{m}$.

TAG-1 antibody cross-linking. This resulted in the colocalization of F3 with TAG-1 in almost all, if not all, clusters (Fig. $10 E-H$ ). On the same coverslip, the cells from the F3-TAG-1-A CHO cell line that expressed F3 alone did not show any clustering of F3 (Fig. 10I). Cross-linking with control anti-HNK-1 mouse IgM antibody did not modify F3 and TAG-1 distribution at the surface of the F3-TAG-1-A CHO cells (data not shown). The association between the two molecules was specific because N-CAM was found in only a few of the clusters after cross-linking of TAG-1 (Fig. 10J-M). Thus, interaction between F3 and TAG-1 can occur in cis after cross-linking at the membrane and is probably dependent on the participation of a linker molecule.

\section{F3 coimmunoprecipitated with TAG-1 in Triton X-100- insoluble microdomains from newborn brain}

To investigate the physiological relevance of the TAG-1/F3 association, we isolated membrane microdomains that are enriched in GPI-anchored molecules from newborn mouse brain. Low sucrose buoyancy, Triton X-100-insoluble microdomains can be isolated from neural tissue and are found to be enriched in GPI-anchored molecules (Olive et al., 1995). They may correspond to functional membrane subdomains where interactions between GPI-anchored molecules, glycolipids, and signaling molecules take place after cellular activation (Sargiacomo et al., 1993; Lisanti et al., 1994).

The concentrations of F3 and TAG-1 in microdomains and microsome fractions from postnatal day 1 mouse brains were analyzed by immunobinding on Western blot. The microsome fraction corresponded to the total membrane proteins. Densitometric analyses indicated that F3 and TAG-1 were three- and fivefold, respectively, more concentrated in microdomains than in the microsome fraction (Fig. 11 $A$ ). This difference in affiliation to membrane microdomains may reflect the diverse associations contracted by these molecules. TAG-1 was immunoprecipitated with rabbit anti-TAG-1 antiserum (TG3) from microdomains solubilized in Tris buffer containing 1\% NP-40 and $0.5 \%$ sodium deoxycholate and after elimination of the nonsolubilized proteins by centrifugation (see Materials and Methods). Proteins contained in the immunoprecipitate were analyzed by gel electrophoresis and immunoblot. Both TAG-1 and F3 molecules were found in the immunoprecipitate (three independent experiments), suggesting that they are physically associated in microdomains (Fig. 11B). As control for the specificity of this association, we showed that N-CAM was not recovered in the TAG-1immunoprecipitate (Fig. $11 B$ ). N-CAM is highly polysialylated in the newborn brain, so that it was not possible to identify clearly the 140 and $180 \mathrm{kDa}$ transmembrane and the $120 \mathrm{kDa}$ glypiated isoforms revealed in the microsome fraction and microdomains (Fig. 11A). However, a decrease in the apparent molecular mass of N-CAM isoforms was observed in microdomains by comparison with the microsome fraction, and a previous study indicated 

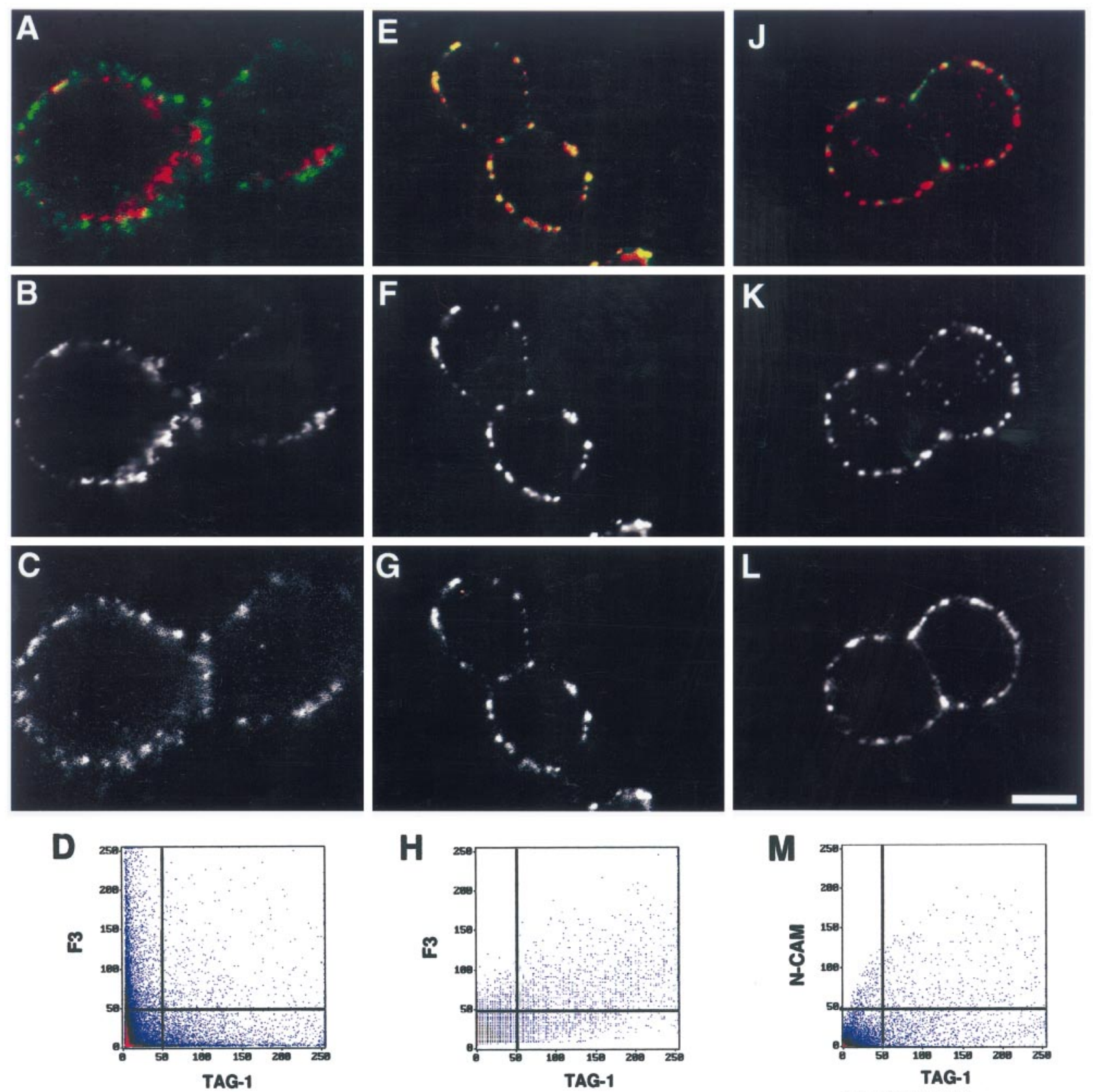

Number of colocateo pixers:
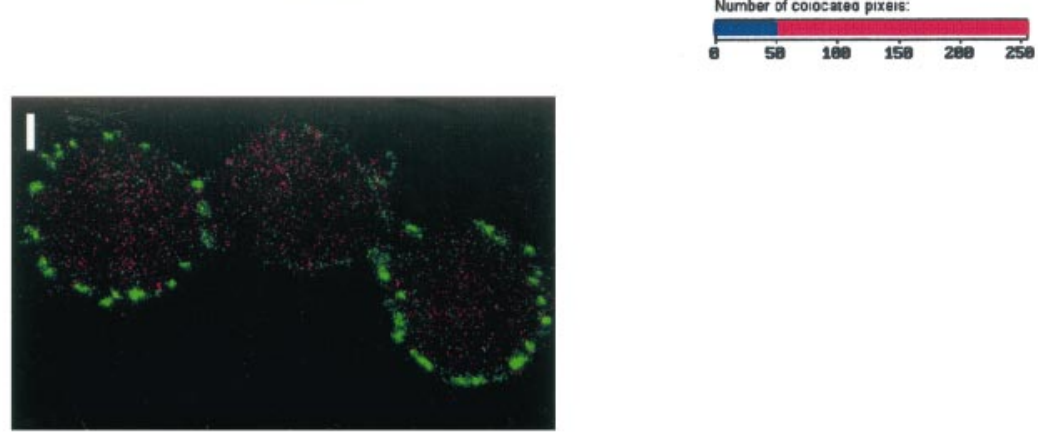

Figure 10. Co-clustering of F3 and TAG-1 at membrane of CHO cells visualized by immunofluorescence. Double-transfected F3-TAG-1-A CHO cells were plated on glass coverslips. $A-D$, TAG-1 $(B)$ and F3 $(C)$ were detected using double-immunofluorescence staining in control conditions and displayed a nonoverlapping distribution pattern $(A, D)$. E-M, Clustering of TAG-1 was induced with anti-TAG-1 mouse IgM monoclonal antibody and Texas Red-conjugated anti-mouse IgM secondary antibody $(F, K)$. Under these conditions, F3 immunoreactivity $(G)$ was induced to co-cluster with TAG-1 $(E)$, whereas N-CAM immunoreactivity $(L)$ only slightly colocalized with TAG-1 clusters $(J)$. A portion of the cell population from the F3-TAG-1-A cell line expressed F3 alone and did not showed clustering of F3 (I). Cells were optically sectioned in the (Figure legend continues) 


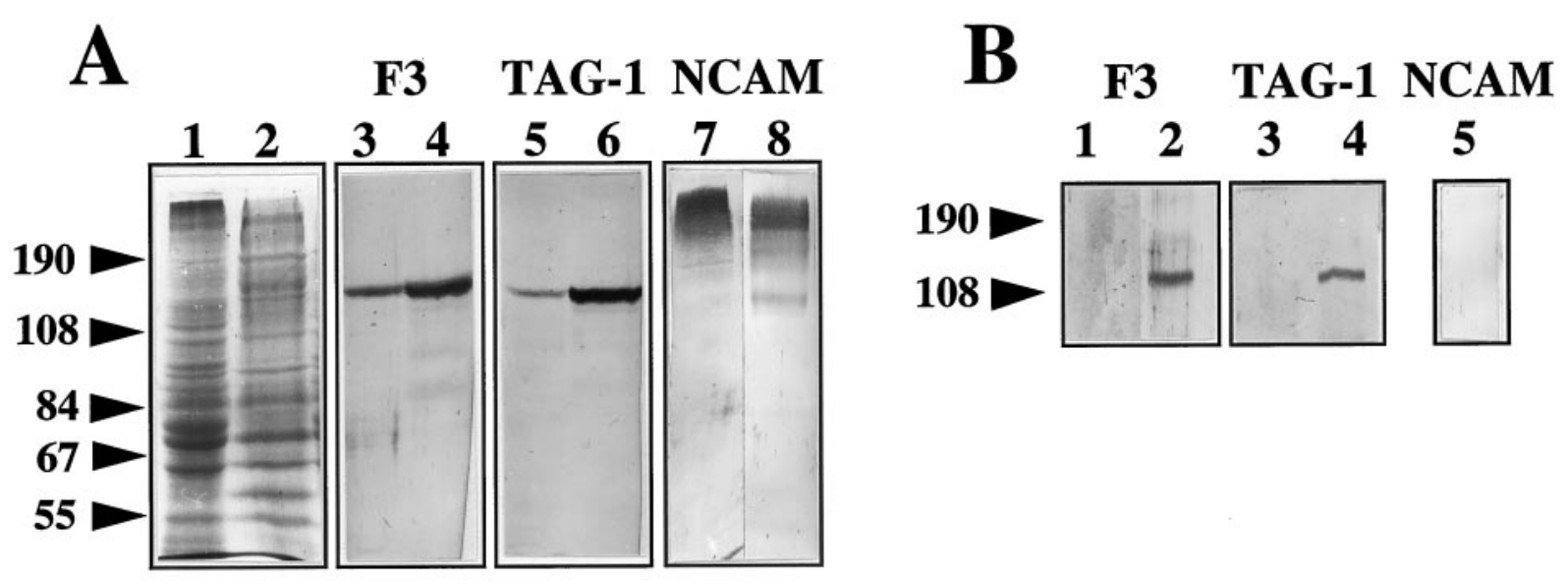

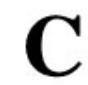

F3 TAG-1 NCAM

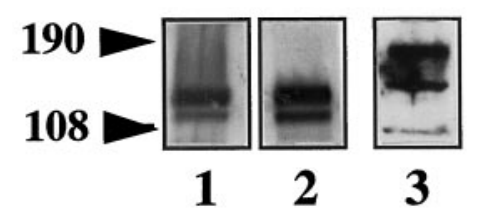

D

\section{F3 TAG-1 NCAM}

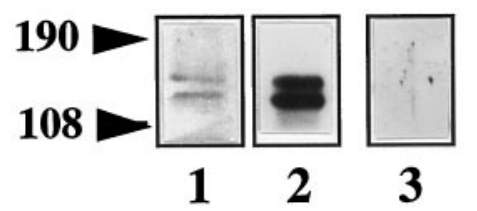

Figure 11. Coimmunoprecipitation of TAG-1 and F3 from Triton X-100-insoluble microdomains of newborn brain and from NP-40 extracts of double-transfected CHO cells. A, F3 and TAG-1 were enriched in microdomains. Fifteen micrograms of protein of microsome fraction (lanes 1, 3, 5, 7) or microdomains (lanes 2, 4, 6, 8) from newborn brain were separated on 7\% SDS-PAGE, stained with Coomassie blue (lanes 1,2) or blotted for anti-F3 (lanes 3, 4), anti-TAG-1 (lanes 5, 6), or anti-N-CAM (lanes 7, 8) immunobinding. B, Immunoprecipitations with rabbit anti-TAG-1 antibodies (lanes 2, $4,5)$ or preimmune rabbit serum (lanes 1,3 ) were performed on $0.5 \mathrm{mg}$ of protein of microdomain solubilized with NP-40 and deoxycholate. Immunoprecipitates were submitted to 7\% SDS-PAGE and immunoblot for anti-F3 (lanes 1, 2), anti-TAG-1 (lanes 3, 4), or anti-N-CAM (lane 5) immunobinding. $C$, F3, TAG-1, and N-CAM expression in F3-TAG-1-A CHO cells analyzed by immunoblot. Thirty micrograms of protein of NP-40-soluble fractions were separated on 7\% SDS-PAGE and blotted for anti-F3 (lane 1), anti-TAG-1 (lane 2), and anti-N-CAM (lane 3) immunobinding. $D$, Immunoprecipitation with mouse IgM monoclonal anti-TAG-1 antibodies was performed on F3-TAG-1-A cells solubilized with NP-40. Immunoprecipitates were divided into three fractions submitted to 7\% SDS-PAGE and blotted for anti-F3 (lane 1), anti-TAG-1 (lane 2), and anti-N-CAM (lane 3) immunobinding.

that only the glypiated isoform of N-CAM is recovered in microdomains from adult brain (Olive et al., 1995).

The interaction between F3 and TAG-1 was investigated in double-transfected $\mathrm{CHO}$ cells by immunoprecipitation from NP-40 detergent extracts. Immunoblotting analysis of the detergent extracts of F3-TAG-1-A cells indicated that both F3 and TAG-1 were expressed as doublets of 135 and $142 \mathrm{kDa}$ in transfected $\mathrm{CHO}$ cells (Fig. 11C). As reported previously (Gennarini et al., 1991), the CHO lines produce two F3-glycosylation variants. As shown in Figure $11 D$, fractions immunoprecipitated with monoclonal anti-TAG-1 IgM antibody contained F3, indicating that a physical link between the two glycoproteins also existed in transfected CHO cells. By contrast, N-CAM was not found in the TAG-1 immunoprecipitate (Fig. 11D). It should be noted that the relative amount of F3 coimmunoprecipitated with TAG-1 was reduced in transfected $\mathrm{CHO}$ cells when compared with microdomains from newborn brain. This might indicate that the association between these two molecules is highly dynamic and requires trans-interaction to be stabilized as was observed with antibody cross-linking experiments on double-transfected $\mathrm{CHO}$ cells.

\section{DISCUSSION}

We have demonstrated here, using an in vitro coculture system, a functional link between the GPI-anchored adhesion glycoproteins F3 and TAG-1. Strikingly, their effect on neurite outgrowth from cerebellar neurons differs according to whether they are presented individually or together. When coexpressed on the same membrane, TAG- 1 is able to negate the inhibitory effect of

\section{$\leftarrow$}

$x-y$ plane in eight slices $(1 \mu \mathrm{m}$ thick); representative midlevel sections are shown ( yellow, colocalized pixels; green, F3 or N-CAM; red, TAG-1). Scale bar: $7 \mu \mathrm{m}$. Cell surface expression of TAG-1 was simultaneously analyzed with F3 or N-CAM expression by two-channel recording $(A, E, I, J)$. Shown are two-dimensional dot blot representations $(D, H, L)$ of the relative fluorescence intensity; $x$-axis, TAG-1 fluorescence; $y$-axis, F3 $(D, H)$ or N-CAM fluorescence $(L)$. 


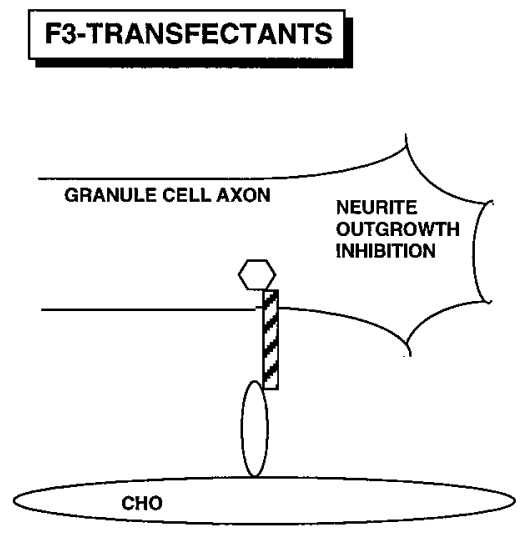

\section{DOUBLE-TRANSFECTANTS}

\section{A- COMPETITION}

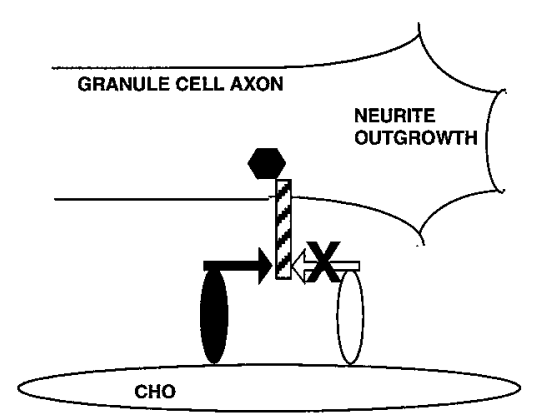

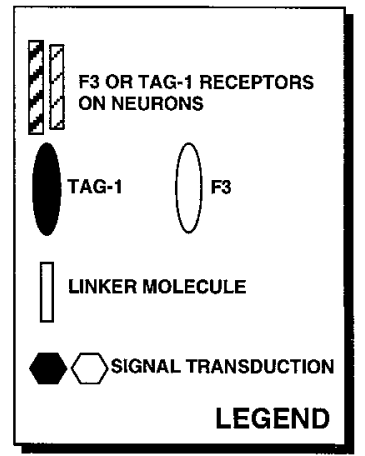

B- CLUSTERING OF RECEPTORS AND LIGANDS

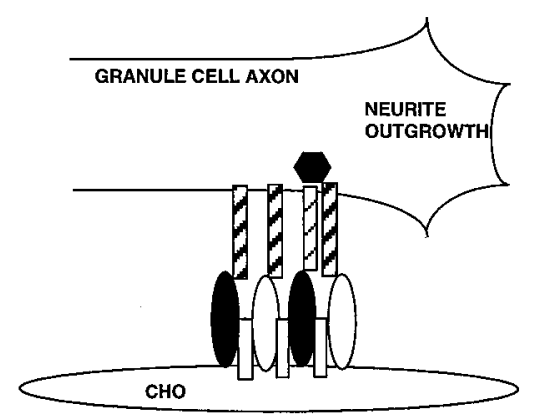

Figure 12. Schematic representation of two possible mechanisms underlying antagonistic effects of TAG-1 and F3 on neurite outgrowth. F3 transfectants inhibit outgrowth of granule cell neurites. TAG-1 coexpressed together with F3 in double transfectants prevents the inhibitory effect of F3. A-COMPETITION, TAG-1 and F3 compete for the same receptor on the responding neuron. Two factors argue in favor of this hypothesis: (1) microspheres conjugated with F3 and TAG-1 bind the same proximal domains of granule cell growth cones; (2) both TAG-1 and F3 exhibit in vitro binding activities toward L1/Ng-CAM and Bravo/Nr-CAM, which are possible candidates as neuronal receptors. B-CLUSTERING OF RECEPTORS $A N D$ LIGANDS, Binding of TAG-1 and F3 to their neuronal receptors leads to the clustering of a multimolecular complex. This hypothesis is supported by clustering experiments achieved with anti-TAG-1 antibodies in double-transfected CHO cells resulting in cis association of F3 and TAG-1. The signal conveyed to neurons via this complex differs from the signal delivered individually by F3 molecules.

F3 on axonal outgrowth and fasciculation. The precise mechanism by which TAG-1 overcomes the inhibitory effect of F3 is unknown. However, we have shown that the neuronal receptors for both molecules display similar location on the growth cones of developing neurites. In addition, we have provided evidence that TAG-1 and F3 may associate on the same membrane: in doubletransfected $\mathrm{CHO}$ cells, antibody-mediated clustering of TAG-1 also induces the co-clustering of F3. Moreover, both molecules are enriched in Triton X-100-insoluble complexes and can be coimmunoprecipitated from newborn brain. This suggests that the coexpression of TAG-1 with F3 in granule cells at early stages of differentiation may be used to modulate F3-mediated interactions with the environment and may have important consequences for cerebellar development.

\section{F3 and TAG-1 display antagonistic activities in vitro for controlling neurite outgrowth and fasciculation of cerebellar granule cells}

F3 can exert highly specific effects on neurite elongation that depend on the neuronal cell type. F3 expressed on the membrane of transfected $\mathrm{CHO}$ cells was shown previously to inhibit neurite outgrowth of cerebellar granule cells (Buttiglione et al., 1996). However, under the same experimental conditions, it stimulates axonal elongation from DRG sensory neurons (Gennarini et al., 1991; Durbec et al., 1992, 1994). TAG-1 also stimulates neurite outgrowth from DRG sensory neurons (Furley et al., 1990; Stoeckli et al., 1991). In contrast, we show here that TAG-1 and F3 act differently on cerebellar granule cells. When expressed individually at the membrane of $\mathrm{CHO}$ cells, TAG-1 does not display any detectable effect on neurite outgrowth of cerebellar neurons, in contrast to the F3 inhibitory effect. However, when coexpressed with F3, TAG-1 prevents the F3-induced effects on neurite outgrowth and fasciculation.

What are the mechanisms underlying the functional link between TAG-1 and F3 ? A first hypothesis is that TAG-1 competes with $\mathrm{F} 3$ for binding sites on the growth cone of responding neurons (Fig. 12A). Binding sites for fluospheres conjugated with F3 and TAG-1 are colocalized on granule cell growth cones. The soluble F3-Fc and TAG-1-Fc chimeras clustered with anti-Fc antibodies also bind neuronal growth cones. Hence, both molecules are individually recognized by developing neurons and are able to modulate neurite outgrowth. The colocalization of their binding sites on cerebellar neurons suggests that they may share similar receptors. Indeed, both TAG-1 and F3 are known to bind the neuronal adhesion molecules $\mathrm{L} 1 / \mathrm{Ng}-\mathrm{CAM}$ and Bravo/Nr- 
CAM (Brümmendorf et al., 1993; Morales et al., 1993; Suter et al., 1995; Stoeckli et al., 1997), both of which are expressed by the cerebellar granule cells (Persohn and Schachner, 1987; Grumet et al., 1991). However, soluble clustered TAG-1-Fc was unable to prevent the F3 inhibitory effect on neurite outgrowth. This observation would tend to favor the hypothesis that TAG-1 does not block the F3-induced effects through competition for a common neuronal receptor. Moreover, the proximity of the binding sites for TAG-1 and F3 does not exclude an alternative hypothesis based on cooperation between the neuronal receptors (Fig. 12B).

Another possibility is that F3 and TAG-1 molecules are able to interact in double transfectants, possibly via a $\mathrm{CHO}$ cell membrane component. This interaction may modify F3 conformation and/or mask the F3 binding site to its neuronal receptor. Alternatively, signals resulting from such a TAG-1/F3 complex can differ from that resulting from the simple binding of F3 with its neuronal receptor (Fig. 12B). Confocal microscopy indicates that TAG-1 and F3 do not colocalize on CHO cell membrane under normal conditions. However, when clustering of TAG-1 is achieved with anti-TAG-1 antibodies to mimic binding with neuronal receptors, the resulting effect is a co-clustering of F3 together with TAG-1 on the CHO membrane. It is thus likely that the binding of TAG-1 and F3 expressed at the CHO membrane with their neuronal receptor(s) leads to the clustering of the two glycoproteins within a multimolecular complex.

\section{F3 is associated with TAG-1 in newborn brain}

Triton X-100-insoluble microdomains from newborn brain were used to evidence a physical association between TAG-1 and F3 in neurons. These insoluble complexes enriched in glycosphingolipid and cholesterol are thought to represent GPI-signaling domains in lymphocytes (Hsi et al., 1989; Stefanova et al., 1991) and neuronal cells (Olive et al., 1995; Henke et al., 1996). F3 and TAG-1 can be coimmunoprecipitated from newborn brain microdomains, but the question remains as to how they associate. If we consider that, in the immature brain, fractions of F3 and TAG-1 are engaged in trans-binding with their receptors, these molecules may associate as the result of an effect within a multimolecular complex. It should be noted that the amount of F3 coimmunoprecipitated with TAG-1 is reduced in $\mathrm{CHO}$ double transfectants when compared with newborn brain microdomains. Therefore, association between the two molecules might require trans-interactions to be stabilized at the $\mathrm{CHO}$ cell membrane as has been shown in the antibody-mediated cross-linking experiments. The association between TAG-1 and F3 is likely to occur in cis, in agreement with the co-clustering of TAG-1 and F3 on the membrane of double-transfected $\mathrm{CHO}$ cells. In addition, in favor of the cis nature of the functional interaction between TAG-1 and F3, we observed that when granule cell aggregates were plated on double transfectants, neurites were especially defasciculated when grown on TAG-1-expressing CHO-F3 cells. However, cross-linking experiments would be useful to confirm that such cis-interaction also occurs in neurons. Such an association could occur either directly or via a linker molecule. To our knowledge, no direct cis-interaction has been reported so far between two GPI-anchored molecules of the Ig superfamily. In addition, we have not detected any direct interaction using microsphere binding assays, although it must be pointed out that our assay favored detection of trans-interactions. If a linker is needed, this molecule could be of the Ig superfamily, in agreement with the multitude of reported interactions between molecules of this family. Possible candidates are L1/NgCAM and Bravo/Nr-CAM
(Brümmendorf and Rathjen, 1996). However, neither L1/NgCAM nor Bravo/Nr-CAM is expressed in CHO cells where a coclustering of TAG-1 and F3 can take place. In this situation, a possible linker could be p190/Caspr, a molecule that has been recently cloned, expressed in ovary cells, and able to form ciscomplex with F3 (Peles et al., 1997).

In our experimental paradigm, $\mathrm{L} 1 / \mathrm{Ng}-\mathrm{CAM}$ and $\mathrm{Bravo} / \mathrm{Nr}$ $\mathrm{CAM}$, if involved in an interaction, are more likely playing the role of trans-interacting molecules on the apposed neuronal membrane. In agreement, a recent study (Volkmer et al., 1996) reports evidence for a functional trans-interaction between F3/F11 and Nr-CAM. On the other hand, the interaction of TAG-1/axonin-1 expressed on commissural axons with $\mathrm{Nr}-\mathrm{CAM}$ on the floor plate results in the masking of floor-plate inhibitory activity for commissural axons (Stoeckli et al., 1997). Therefore, in both the cerebellar granule cells and commissural axons, TAG-1/axonin-1 is able to negate an inhibitory signal.

The question of the molecular composition of the F3/TAG-1 complex merits further exploration. The assembly of functional cell surface molecules is a common theme in cell-cell communication, and the signal conveyed to neurons via these complexes may differ from the signals delivered by individual molecules. There is evidence to suggest that Ig-like family members presented in combination affect axonal growth in a different way than when molecules are presented individually. For example, Bravo/ $\mathrm{Nr}-\mathrm{CAM}$ and L1/Ng-CAM display synergistic neurite outgrowthpromoting activity on retinal neurons, whereas Bravo/Nr-CAM alone does not support neurite growth (Morales et al., 1996). Moreover, Ng-CAM/L1 and axonin-1/TAG-1 interact in cis and cooperate in neurite outgrowth promotion (Buchstaller et al., 1996). Finally, contactin/F11/F3 may complex in cis with NrCAM to mediate RPTP $\beta$ activation of neurite outgrowth (Sakurai et al., 1997).

\section{Physiological relevance of the interaction between TAG-1 and F3 during cerebellar morphogenesis}

The functional characterization of TAG-1 and F3 in vitro fits well with their temporal pattern of expression during cerebellar morphogenesis. TAG-1 and F3 are highly expressed on cerebellar granule cells during the first postnatal week, when the parallel fibers are elongating. Immunoelectron microscopy data have indicated that the two glycoproteins coexist in the upper part of the molecular layer where the growing parallel fibers are deposited (Yamamoto et al., 1990; Faivre-Sarrailh et al., 1992). As demonstrated using double-staining immunofluorescence on cerebellar culture, TAG-1 and F3 partially display an overlapping distribution on granule cell axons. Moreover, fractions of the two molecules were shown to be physically associated in Triton X-100insoluble microdomains prepared at this stage. This suggests that clustering of TAG-1 and F3 may occur at the surface of granule cell axons in vivo when engaged in binding with their receptors on a neighboring axon within a fascicle. In this situation, a permissive signal for axonal elongation would be delivered. These two molecules also display distinct distribution patterns: TAG-1 is found on the growth cones whereas F3 is not, indicating that TAG-1 is able to play the role of a receptor for guidance cues during axogenesis. In more mature cerebellum, TAG-1 is no longer expressed and F3 is still present on the parallel fibers, including their presynaptic varicosities. At the end of morphogenesis, F3 may participate in stabilizing the mature axonal network through its inhibitory effect on neurite outgrowth.

In conclusion, the neuronal adhesion glycoprotein F3/F11 is 
able to both stimulate and inhibit neurite outgrowth in various neuronal cell types. The nature of the regulatory activity it displays might depend on the interplay of associations it contracts with molecules expressed in its environment. The formation of multimolecular complexes might be a potent way to integrate environmental information. It remains to be determined how these complexes interact with the signal transduction pathways that they trigger.

\section{REFERENCES}

Altman J (1972) Postnatal development of the cerebellar cortex in the rat. III: Maturation of the components of the granular layer. J Comp Neurol 145:465-514.

Bailly Y, Kyriakopoulou K, Delhaye-Bouchaud N, Mariani J, Karagogeos SD (1996) Cerebellar granule cell differentiation in mutant and $\mathrm{X}$-irradiated rodents revealed by the expression of the neural adhesion molecule TAG-1. J Comp Neurol 369:150-161.

Brümmendorf T, Rathjen F (1996) Structure/function relationships of axon-associated adhesion receptors of the immunoglobulin superfamily. Curr Opin Neurobiol 6:584-592.

Brümmendorf T, Hubert M, Treubert U, Leuschner R, Tarnok A, Rathjen F (1993) The axonal recognition molecule F11 is a multifunctional protein: specific domains mediate interactions with $\mathrm{Ng}$-CAM and restrictin. Neuron 10:711-727.

Buchstaller A, Kunz S, Berger P, Kunz B, Ziegler U, Rader C, Sonderegger P (1996) Cell adhesion molecules NgCAM and axonin-1 form heterodimers in the neuronal membrane and cooperate in neurite outgrowth promotion. J Cell Biol 135:1593-1607.

Buttiglione M, Revest JM, Rougon G, Faivre-Sarrailh C (1996) F3 neuronal adhesion molecule controls outgrowth and fasciculation of cerebellar granule cell neurites: a cell-type specific effect mediated by the Ig-like domains. Mol Cell Neurosci 8:53-69.

Durbec P, Gennarini G, Goridis C, Rougon G (1992) A soluble form of the F3 neuronal cell adhesion molecule promotes neurite outgrowth. J Cell Biol 117:877-887.

Durbec P, Gennarini G, Buttiglione M, Gomez S, Rougon G (1994) Different domains of the F3 neuronal adhesion molecule are involved in adhesion and neurite outgrowth promotion. Eur J Neurosci 6:461-472.

Faivre-Sarrailh C, Gennarini G, Goridis C, Rougon G (1992) F3/F11 cell surface molecule expression in the developing mouse cerebellum is polarized at synaptic sites and within granule cells. J Neurosci 12:257-267.

Felsenfeld DP, Hynes MA, Skoler KM, Furley AJ, Jessel TM (1994) TAG-1 can mediate homophilic binding but neurite outgrowth on TAG-1 requires an L1-like molecule and $\beta 1$ integrins. Neuron 12:675-690.

Furley AJ, Morton SB, Manalo D, Karagogeos D, Dodd J, Jessell TM (1990) The axonal glycoprotein TAG-1 is an immunoglobulin superfamily member with neurite outgrowth promoting activity. Cell 61:157-170.

Gennarini G, Cibelli G, Rougon G, Mattei M, Goridis C (1989) The mouse neuronal cell surface protein F3: a phosphatidylinositolanchored member of the immunoglobulin superfamily related to the chicken contactin. J Cell Biol 109:775-788.

Gennarini G, Durbec P, Boned A, Rougon G, Goridis C (1991) Transfected F3/F11 neuronal cell surface protein mediates intercellular adhesion and promotes neurites outgrowth. Neuron 6:595-606.

Grumet M, Mauro V, Burgoon M, Edelman G, Cunningham B (1991) Structure of a new nervous system glycoprotein, Nr-CAM, and its relationship to subgroups of neural cell adhesion molecules. J Cell Biol 113:1399-1412.

Hekmat A, Bitter-Suermann D, Schachner M (1990) Immunocytological localization of the highly polysialylated form of the neural cell adhesion molecule during development of the murine cerebellar cortex. J Comp Neurol 291:457-467.

Henke RC, Hancox KA, Jeffery PL (1996) Characterization of two distinct populations of detergent resistant membrane complexes isolated from chick brain tissues. J Neurosci Res 45:617-630.

Hsi E, Siegel DJ, Minami Y, Luong E, Klausner R, Samelson L (1989) T cell activation induces rapid tyrosine phosphorylation of a limited number of cellular substrates. J Biol Chem 264:10836-10842.
Kuhn TB, Stoeckli ET, Condrau MA, Rathjen FG, Sonderegger P (1991) Neurite outgrowth on immobilized axonin-1 is mediated by a heterophilic interaction with L1 (G4). J Cell Biol 115:1113-1126.

Lehmann JM, Riethmuller G, Johnson JP (1989) MUC18, a marker of tumor progression in human melanoma, shows sequence similarity to the neural cell adhesion molecules of the immunoglobulin superfamily. Proc Natl Acad Sci USA 86:9891-9895.

Lin CH, Forscher P (1995) Growth cone advance is inversely proportional to retrograde F-actin flow. Neuron 14:763-771.

Lisanti M, Scherer P, Vidugiriene J, Tang Z, Hermanowski-Vosatka A, Tu Y, Cook F, Sargicomo M (1994) Characterization of caveolin-rich membrane domains isolated from an endothelial-rich source: implication for human disease. J Cell Biol 126:111-126.

Morales G, Hubert M, Brümmendorf T, Treubert U, Tarnok A, Schwarz U, Rathjen F (1993) Induction of axonal growth by heterophilic interactions between the cell surface recognition proteins F11 and NrCAM/Bravo. Neuron 11:1113-1122.

Morales G, Sanchez-Puelles JM, Schwarz U, de la Rosa EJ (1996) Synergistic neurite-outgrowth promoting activity of two related axonal proteins, Bravo/Nr-CAM and G4/Ng-CAM, in chicken retinal explants. Eur J Neurosci 8:1098-1105.

Olive S, Dubois C, Schachner M, Rougon G (1995) The F3 neuronal GPI-linked molecule is localized to glycolipid-enriched membrane subdomains and interacts with L1 and fyn-kinase in cerebellum. J Neurochem 65:2307-2317.

Peles E, Nativ C, Lustig M, Grumet M, Schilling J, Martinez R, Plowman GD, Schlessinger J (1997) Identification of a novel contactinassociated transmembrane receptor with multiple domains implicated in protein-protein interactions. EMBO J 16:978-988.

Persohn E, Schachner M (1987) Immunoelectron microscopic localization of the neural adhesion molecules L1 and N-CAM during postnatal development of the rat cerebellum. J Cell Biol 105:569-576.

Rougon G, Marshak D (1986) Structural and immunological characterization of the amino-terminal domain of mammalian neural cell adhesion molecules. J Biol Chem 261:3396-3401.

Sakurai T, Lustig M, Nativ M, Hemperly JJ, Schlessinger J, Peles E, Grumet M (1997) Induction of neurite outgrowth through contactin and Nr-CAM by extracellular regions of glial receptor tyrosine phosphatase $\beta$. J Cell Biol 136:907-918.

Sargiacomo M, Sudol M, Tang TI, Lisanti M (1993) Signal transducing molecules and glycosyl-phosphatidylinositol-linked proteins form a caveolin-rich insoluble complex in MDCK cells. J Cell Biol 122:789-807.

Stefanova I, Horejsi V, Ansotegui I, Knapp JW, Stockinger H (1991) GPI-anchored cell-surface molecules complexed to protein tyrosine kinases. Science 254:1016-1019.

Stoeckli ET, Kuhn TB, Duc CO, Ruegg MA, Sonderegger P (1991) The axonally secreted protein axonin-1 is a potent substratum for neurite growth. J Cell Biol 112:449-455.

Stoeckli ET, Sonderegger P, Pollerberg GE, Landmesser LT (1997) Interference with axonin-1 and NrCAM interactions unmasks a floorplate activity inhibitory for commissural axons. Neuron 18:209-221.

Suter DM, Pollerberg GE, Buchstaller A, Giger RJ, Dreyer WJ, Sonderegger P (1995) Binding between the neural cell adhesion molecules axonin-1 and $\mathrm{Nr}-\mathrm{CAM} /$ Bravo is involved in neuron-glia interaction. J Cell Biol 131:1067-1081.

Tsiotra PC, Karagogeos D, Theodorakis K, Michaelidis TM, Modi WS, Furley A, Jessell TM, Papamatheakis J (1993) Isolation of the cDNA and chromosomal localization of the gene (TAX1) encoding the human axonal glycoprotein TAG-1. Genomics 18:562-567.

Tsiotra PC, Theodorakis K, Papamatheakis J, Karagogeos D (1996) The fibronectin domains of the neural adhesion molecule TAX-1 are necessary and sufficient for homophilic binding. J Biol Chem 271:29216-29222.

Volkmer H, Leuschner R, Lacharias U, Rathjen F (1996) Neurofascin induces neurites by heterophilic interactions with axonal NrCAM while NrCAM requires F11 on the axonal surface to extend neurites. J Cell Biol 135:1059-1069.

Yamamoto M, Hassinger L, Crandall JE (1990) Ultrastructural localization of stage-specific neurite associated proteins in the developing rat cerebral and cerebellar cortices. J Neurocytol 19:619-627. 